\title{
Larval Development of the European Lobster and How Small Heterochronic Shifts Lead to a More Pronounced Metamorphosis
}

\author{
Marie A. I. N. Rötzer and Joachim T. Haug \\ Functional Morphology, Department of Biology II and GeoBio-Center, Ludwig-Maximilians University of Munich, \\ 82151 Planegg-Martinsried, Germany
}

Correspondence should be addressed to Joachim T. Haug; joachim.haug@palaeo-evo-devo.info

Received 26 September 2014; Revised 2 December 2014; Accepted 2 December 2014

Academic Editor: Iain J. McGaw

Copyright (C) 2015 M. A. I. N. Rötzer and J. T. Haug. This is an open access article distributed under the Creative Commons Attribution License, which permits unrestricted use, distribution, and reproduction in any medium, provided the original work is properly cited.

\begin{abstract}
We redescribe the larval stages of the European lobster, Homarus gammarus, based on autofluorescence composite imaging. We focus on larval stages (II) to (IV). Compared to the American lobster, Homarus americanus, differences are most apparent in stage (III). This stage appears more mature in H. gammarus; for example, the rostrum is already curved and bears spines, and the appendages are better developed and longer and more differentiated. In H. americanus stage (III) shows a stronger resemblance to stage (II). As a result of the morphology of stage (III), the "metamorphic" moult between stage (III) and stage (IV) in H. gammarus is less drastic than in H. americanus. Metamorphosis is characterised by two criteria. It involves (1) a drastic change in morphology in (2) a short amount of time. It has hence been suggested that a more pronounced metamorphosis evolves by two factors affecting these criteria, namely, (1) the evolution of specialised larval features, which increase the morphological disparity between larva and adult that makes the change of morphology more drastic, and (2) the skipping of entire stages. This means larval forms ancestrally moult over several intermediate forms into the definite adult morphology. Yet, in more derived forms the stages with intermediate morphologies are no longer expressed; highly specialized larvae moult into the adult within a single moult (in the most extreme case) hence bridging the morphologies of larvae and adult in a shorter amount of time. The example of the two Homarus species demonstrates that this explanation is not the only possible one. Additionally, differences of a single larval stage (in this case larval stage (III)) can lead to a more or less metamorphic-appearing ontogenetic sequence.
\end{abstract}

\section{Introduction}

The European lobster, Homarus gammarus (Linnaeus, 1758), shows an abbreviated larval development, as do other nephropid lobsters. Plesiomorphically (e.g., [1-4]) eucrustaceans develop progressively through a rather long and gradual larval sequence, in some cases with several larval phases $[5,6]$. Among decapods, natant shrimps (e.g., $[5,7-$ 11]) as well as reptantian lobsters retain this pattern and can develop through long larval sequences (e.g., mud lobsters [12]; slipper lobsters [13-15]).

The European lobster (as other crustaceans) grows by moulting, which decreases in frequency later in development but continues in adults their whole life. While moulting, water is absorbed by the body tissue to swell and rupture the outer exoskeleton. Further swelling occurs, and a new exoskeleton starts to harden. Due to this process, lobsters (as all arthropods) develop in (pseudo-)discrete postembryonic stages.

H. gammarus hatches as the so-called prelarva; it stays on the maternal pleopods after hatching [16]. The prelarva is followed by three larval stages (zoea stages sensu [6]), which are omnivorous and pelagic, more precisely, they float in the surface layers. The fourth larval stage, often unfortunately termed "postlarva," is a megalopa stage (sensu [6]). Following chemical cues, the larva moves to the ground (e.g., [17]), close to the area of spawning [18], to search for a suitable settlement substrate, and thereby changes to a benthic lifestyle. The megalopa is followed by the first juvenile stage (stage (V)). The entire larval development is completed within a relatively short period of time, in about three weeks. Yet, the exact time depends on external factors. The main influence on 
the rate of development is temperature. With optimal water temperature around $20-22^{\circ} \mathrm{C}$ for moulting, the larval period lasts about 12 days [19]. Other general factors that affect moulting in decapods are salinity, light intensity, habitat size, social interaction, and water quality [20].

H. gammarus, as many other representatives of Nephropidae (true lobsters [21]), has three zoea stages and one megalopa stage [22]. This is also true for the sister species of H. gammarus, Homarus americanus (Milne Edwards, 1873), the American (clawed) lobster [23]. For distinguishing the stages in premolt samples, setal development gives important clues [24].

Charmantier et al. [23] identified the moult from the last zoea to the megalopa as a metamorphosis in H. americanus. This metamorphosis is both morphological and ecological, coupled to the shift in mode of life from planktic to benthic. The authors furthermore stated that, except for size and minor biometric differences, the morphology of zoea and megalopa stages of $H$. gammarus is nearly identical to those of $H$. americanus.

Interestingly, an intermediate stage between the last zoea and the megalopa has been reported for both the European lobster (e.g., [25]) and the American lobster (e.g., [26]). Such "early megalopa" stages have also been reported from other extant and fossil eumalacostracan crustaceans [2732]. Charmantier and Aiken [33] reported that such a stage occurs only rarely under natural conditions (mainly if they are unfavourable) but could be induced by eyestalk ablation in stage (II).

Metamorphosis in general is challenging to understand. The rather short larval sequence and the occurrence of "intermetamorphic" stages make homarid species a possible model system to achieve deeper insights into mechanisms and evolution of metamorphosis in arthropods. Metamorphosis in general describes the transformation from autonomous larvae to an adult. It is performed in a short time frame, for arthropods ideally from one molt to another, contrary to a gradual transformation, with one or multiple major changes in the anatomical parts involving a functional change. Yet, Haug and Haug [4] have pointed out that the decision between what is metamorphic and what is not is not trivial. In many cases it is only possible to state that a certain metamorphic pattern is more or less metamorphic than another one.

We redescribe the larval stages of $H$. gammarus with modern imaging techniques in order to compare them to those of the American lobster. We especially focus on the stages around the metamorphic moult in order to better understand the phenomenon of metamorphosis.

\section{Material and Methods}

2.1. Material. Several immature specimens of the European lobster Homarus gammarus were the basis for the present investigation. In detail one specimen of zoea (I), two specimens of zoea (II), five specimens of zoea (III), and five specimens of larva (IV) (megalopa) were photographed. All specimens are deposited in the Zoologische Staatssammlung München under repository numbers ZSMA20147001-ZSMA20147008. The focus lay on the larval stages (II), (III) (zoea 2 and 3), and (IV) (megalopa). An additional five specimens of zoea (III) were inspected but proved to show the same type of variation as the photographed specimens. All specimens came from the research station Helgoland, North Sea, Germany. Specimens were fixed and stored in $70 \%$ ethanol.

2.2. Methods. All specimens were documented in $70 \%$ ethanol on a Keyence BZ-9000 fluorescence microscope with either a $2 \mathrm{x}, 4 \mathrm{x}$, or $10 \mathrm{x}$ objective (resulting in about $20 \mathrm{x}$, $40 \mathrm{x}$, and 100x magnification; in few cases additionally the zoom function of the camera was employed) depending on the sizes of the body parts. UV light $(377 \mathrm{~nm})$ was used for illumination, using the autofluorescence capacities of the specimens [34]. For high-resolution images composite imaging was applied [34-36]; the processing was accomplished first with the computer software CombineZM, an image stacking software, to assemble the stacks to sharp images. ImageJ was used to crop all images as CombineZM adds an artificial rim. Microsoft Image Composite Editor was used to merge different image detail to panorama images. Finally the pictures were edited in Adobe Photoshop CS 5 (optimizing the histogram and sharpness, manual removing of dirt particles, etc.).

Photographs of structures with setae were taken twice, under different exposure times. This was necessary as setae have a weaker autofluorescence. Hence besides an image well depicting surface details of the appendages, a second image was taken with the exposure adjustments on the setae, while other structures were overexposed.

Afterwards, this image was placed in Adobe Photoshop as a separate layer above the image with shorter exposure time. Alignment of the upper layer with the lower one was based on significant landmark structures, that is, structures that are visible and prominent in both images.

The magic wand tool was applied to mark overexposed (hence white) areas; a high feather was applied to the edge, and then these areas were cut out. The resulting image shows all parts well illuminated, that is, neither overexposed, nor too dark (see also [37]).

Published drawings of Homarus americanus larval stages (II), (III), and (IV) were redrawn and modified in Adobe Illustrator CS 5 based on Charmantier et al. [23]. The intermediate stage (IVa) (Figure 12) was redrawn by Charmantier and Aiken [33].

Usually, in description of larval sequences, at first one stage is entirely described, then the next one, and so on. As we are focusing here on structural changes between the stages, we have chosen to present the corresponding structures of the different stages next to each other. Hence, we first describe, for example, the antennula for all stages, then the antenna for all stages, and so on, in order to improve the comparability.

\section{Results}

\subsection{Morphological Description}

Body. (Figures 1 and 2) All stages: subdivided into 20 segments with two main tagmata, the cephalothorax and 


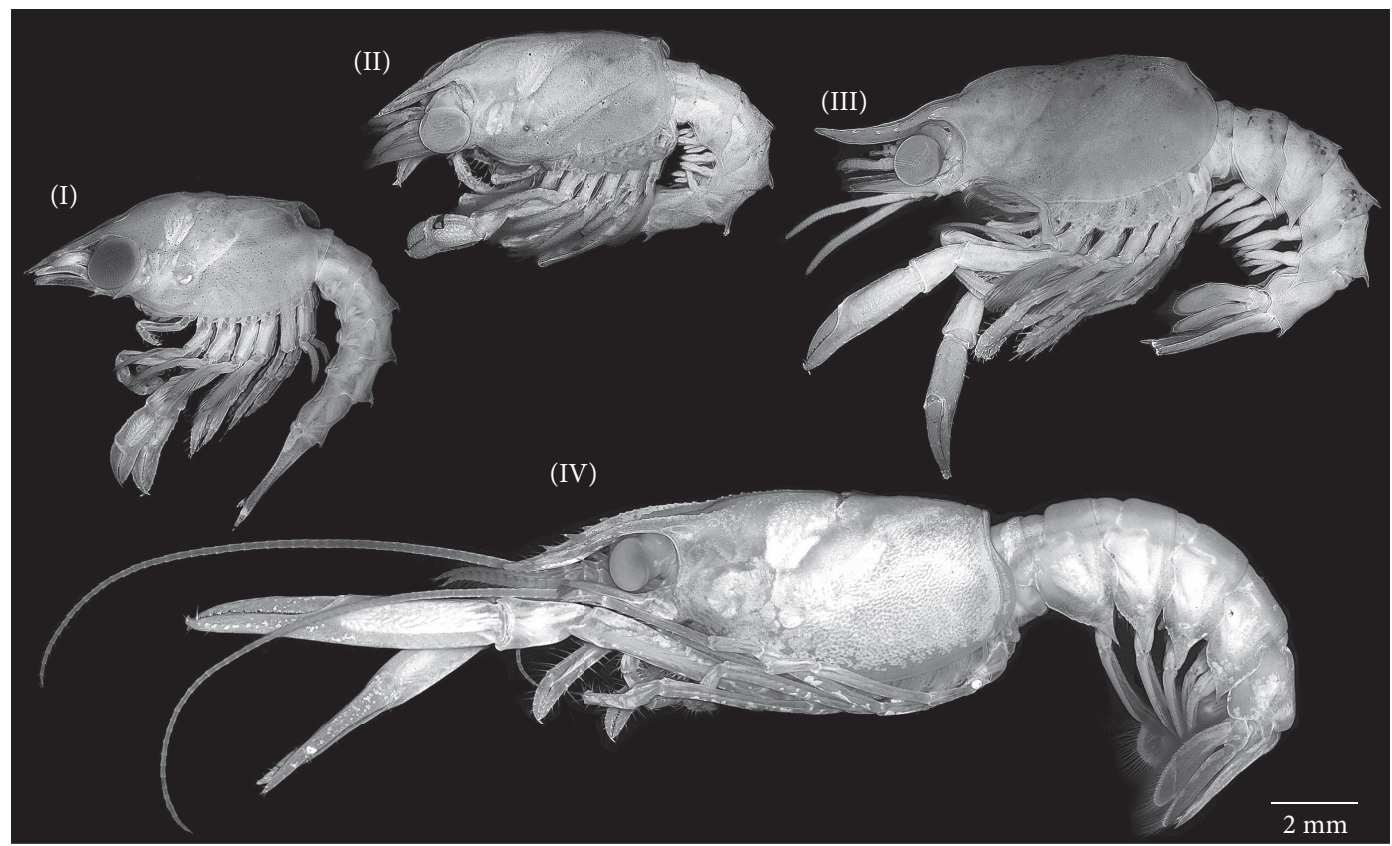

FIGURE 1: Larval stages of Homarus gammarus labelled with roman numerals. All specimens in lateral view and to the same scale for size comparison.

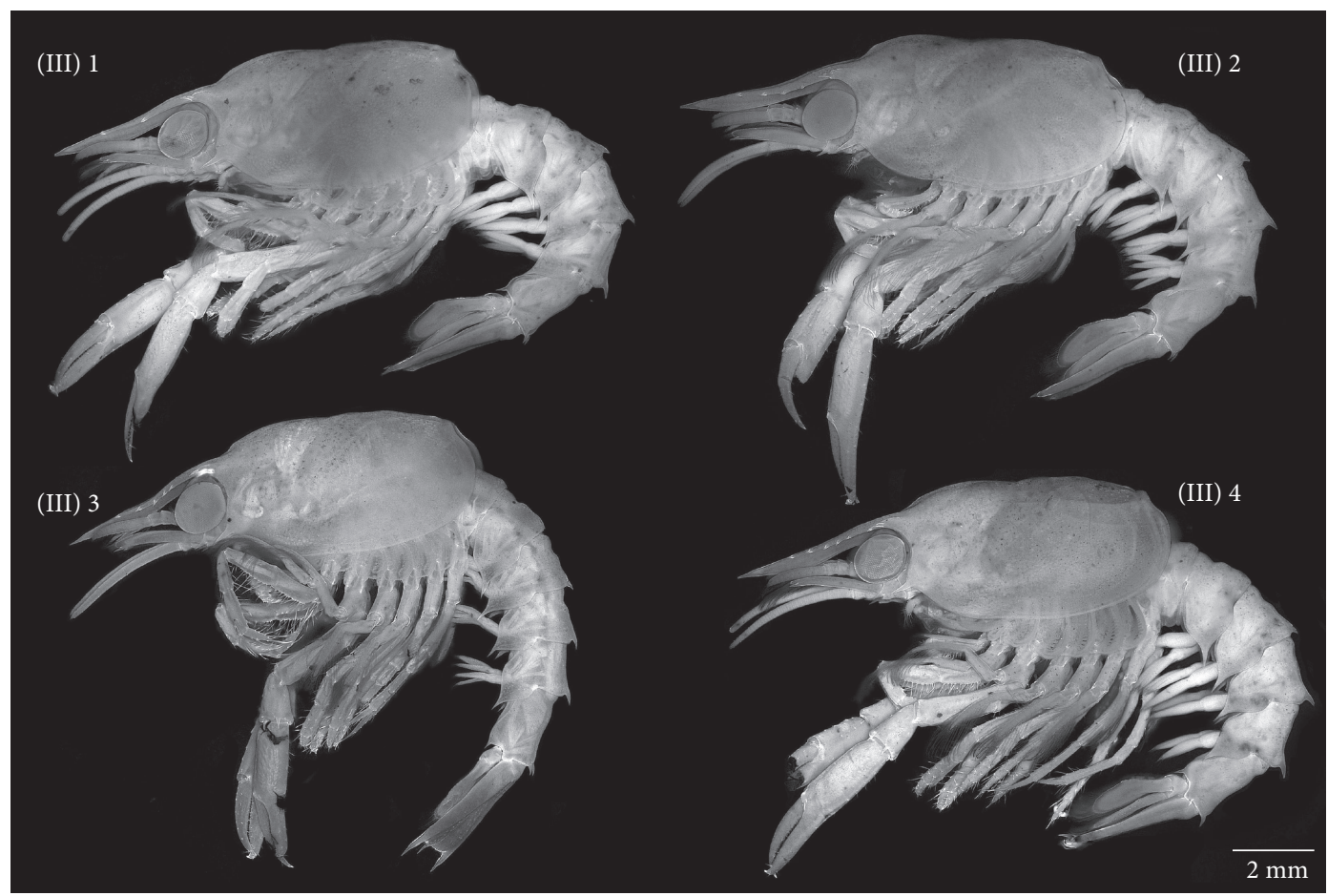

FIGURE 2: Additional specimens of larval stage (III). These show a certain degree of variability.

pleon; the pleon is followed by the nonsomitic telson. The cephalothorax consists of fourteen segments, the pleon of six segments.

Carapace. All stages: large, shield-like cuticular structure formed by dorsal region of cephalothoracic segments. It bears a cone-shaped rostrum anteriorly; carapace encloses gill-bearing bases of thoracopods and thus forms branchial chambers.

Rostrum. Stage (II) (Figure 3): unpaired anterior extension of carapace. Projects between eyestalks and represents extension 

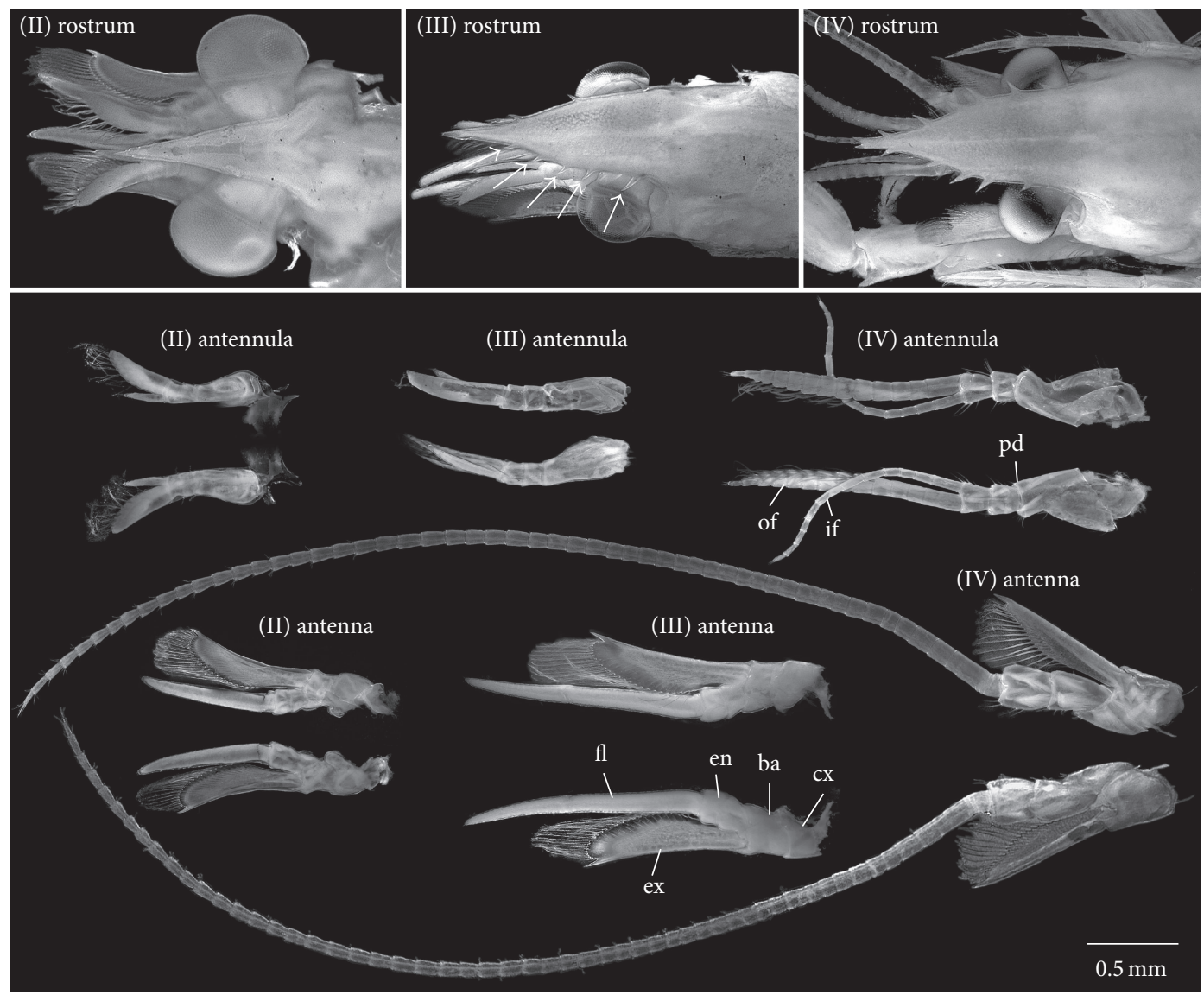

FIGURE 3: Anterior structures of larval stages (II) to (IV) of Homarus gammarus. Rostra not to scale; note the spines (marked by arrows) in stage (III). Antennula and antenna. Right appendage in anterior (upper row) and posterior (lower row), besides (II) antenna, which is a left one and flipped. Labeling only given in one instance due to the similarity of the structures throughout all stages. ba $=\mathrm{basipod} ; \mathrm{cx}=\mathrm{coxa}$; en = endopod; ex = exopod; $\mathrm{fl}=$ flagellum; if = inner flagellum; of = outer flagellum.

of frontal region. Stage (III): rostrum is further extended to the front, bears spines. Stage (IV): front of the rostrum now bifurcate, that is, with a pair of small spines anteriorly.

Pleon. All stages: posterior division of body. It consists of six pleomeres, each bearing pair of appendages (pleopods). Sixth pleomere articulates with telson. Stages (II) and (III): tergites with pronounced tergopleura, which are laterally slightly widening arrowing into distinct tip. Stage (IV): tergopleura become wider proximally but are still distinctly pointed and show serrations along the margin.

Structures of Ocular Segment. Eye (in all stages): consisting of numerous ommatidia covered by cornea; stalked. Labrum (in all stages): (Figure 4) relatively large, unpaired, fleshy lobe in front of and partially covering mouth.

Appendage of 1st Postocular Segment (Antennula). (Figure 3) All stages: first (smaller) antenna with aesthetascs (a series of small sensory projections on outer flagellum of antennule). Stage (II): peduncle with three elements, with scale-like outer flagellum which possesses seta and smaller inner flagellum of same length. Stage (III): only few changes, slightly increased size. Stage (IV): slim outer flagellum and delicate inner flagellum; both are subdivided into numerous small elements (flagellomeres).

Appendage of 2nd Postocular Segment (Antenna). (Figure 3) All stages: biramous, composed of coxa, basipod (together forming the protopod) endopod, and exopod. Bears pore of antennal gland. Endopod with proximal element and distal flagellum. Stage (II): endopod and exopod show same length. Stage (III): twice the size of stage (II); endopod protrudes beyond the exopod. Stage (IV): large extension (about fivefold length) of the flagellum in proportion to the exopod.

Appendage of 3rd Postocular Segment (Mandible). (Figure 4) All stages: Anteriormost mouthpart on underside of head. With large coxa, with terminal molar, and with incisor processes as well as distal palp; exopod absent. Stages (II) and (III): well-developed. Stage (IV): better defined palp with three elements.

Paragnath (Elevation of Sternal Region of 3rd Postocular Segment). (Figure 4) All stages: lip-like structure posterior to mouth on underside of head, guiding the mandible movements. 

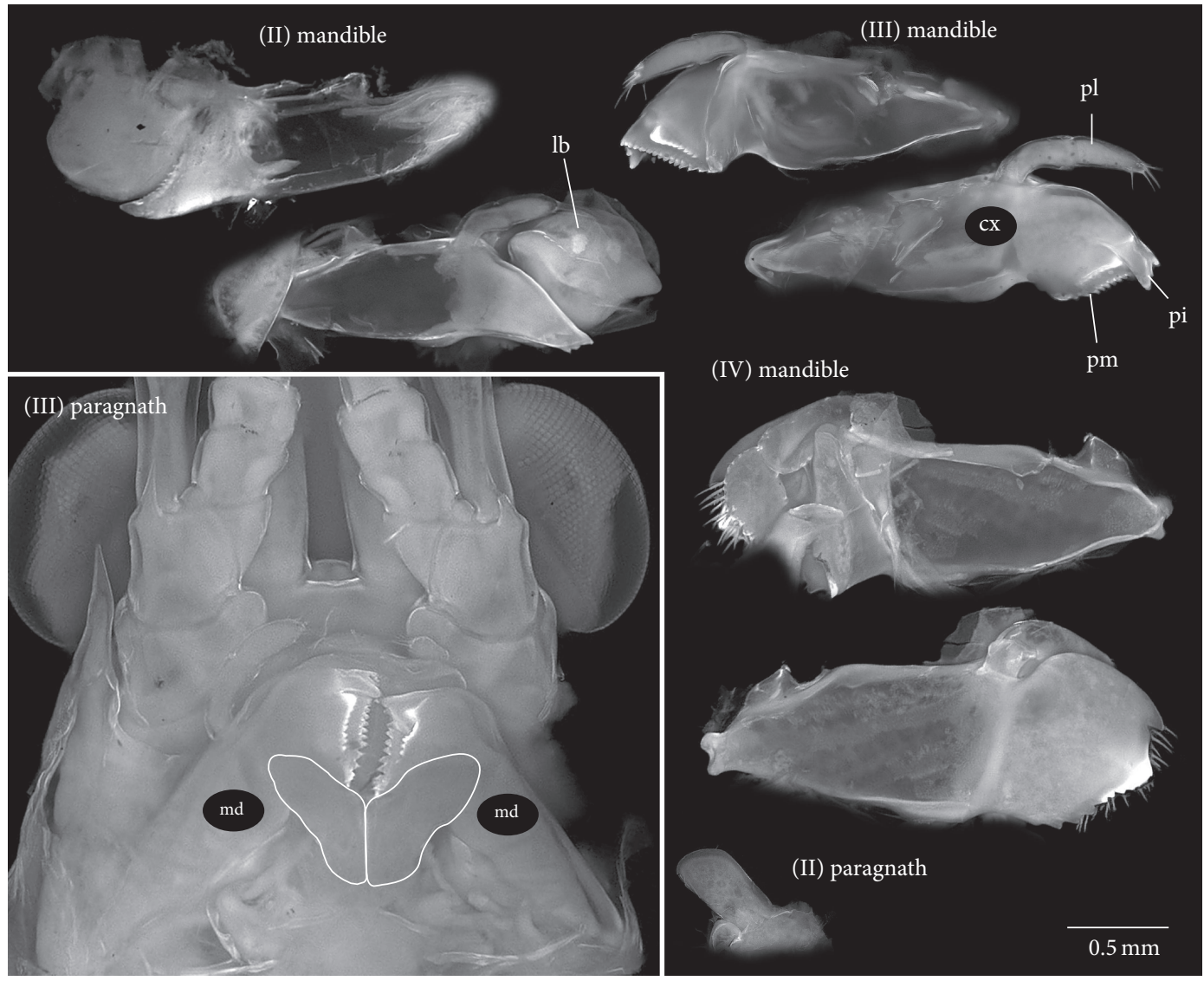

FIGURE 4: Mandible and paragnaths of larval stages (II) to (IV) of Homarus gammarus. Right mandible in anterior (top) and posterior view (bottom). Note that (II) mandible and (IV) mandible are left mandibles flipped, while (III) mandible is a right mandible. (II) Mandible is still attached to labrum. (III) Paragnath shown in situ, marked by hand due to low contrast against mandible. (II) Paragnath, right, in posterior view. $\mathrm{lb}=$ labrum; $\mathrm{md}=$ mandible; $\mathrm{pi}=$ pars incisivus; $\mathrm{pl}=$ palpus; $\mathrm{pm}=$ pars molaris.

Appendage of 4th Postocular Segment (Maxillula). (Figure 5) All stages: second mouthpart on underside of head. Stages (II) and (III): well-developed, with coxa and basipod both drawn out into pronounced lobate endites and small undivided endopod. Stage (IV): endopod subdivided into two elements, distal element curving.

Appendage of 5th Postocular Segment ("Second" Maxilla). (Figure 5) All stages: third mouthpart on underside of head. With coxa and basipod, both drawn out into two pronounced lobate endites each, endopod and exopod. Endopod not subdivided, exopod large, bilobed with a distal and proximal lobe. Distinct increased size from stage (II) to stage (IV) (about 420\%); in comparison body size increases about $150 \%$ (oriented by carapace).

Appendage of 6th Postocular Segment (1st Maxilliped; 1st Thoracopod). (Figure 6) All stages: first of three pairs of mouthparts posterior to maxillae on underside of head. Consist of protopod, with coxa and basipod, from which endopod and exopod arise. Coxa and basipod with endites; basipodal endite very prominent, endopod consists of two elongate elements. Elongate exopod, longer than endopod, large bilobed epipod with large proximal lobe and small distal lobe.
Appendage of 7th Postocular Segment (2nd Maxilliped; 2nd Thoracopod). (Figure 6) All stages: Consisting of coxa and basipod, bearing endopod, and exopod. Coxa and basipod without pronounced endites. Endopod with five elements (ischium, merus, carpus, propodus, and dactylus). Strong bent (jack-knifing) in element 3 (carpus), leading to a functional subchela. Stage (II): exopod uniform scale, reaching element 2 of endopod. Stage (III): slightly longer. Stage (IV): significantly longer, now subdivided into annuli.

Appendage of 8th Postocular Segment (3rd Maxilliped; 3rd Thoracopod). (Figure 7) All stages: Consisting of coxa and basipod, bearing endopod and exopod. Coxa and basipod without pronounced endites. Endopod with five elements (ischium, merus, carpus, propodus, and dactylus). Strong bent in element 3 (carpus), leading to a functional subchela. No significant size gain throughout observed ontogeny. Stages (II) and (III): exopod uniform scale, reaching element 2 of endopod. Stage (IV): now subdivided into annuli.

Appendage of 9th Postocular Segment (4th Thoracopod). (Figure 7) All stages: consisting of coxa and basipod from the latter arise endopod and exopod. Endopod with five elements (ischium, merus, carpus, propodus, and dactylus). Distal part of this appendage is modified to a heavy claw 


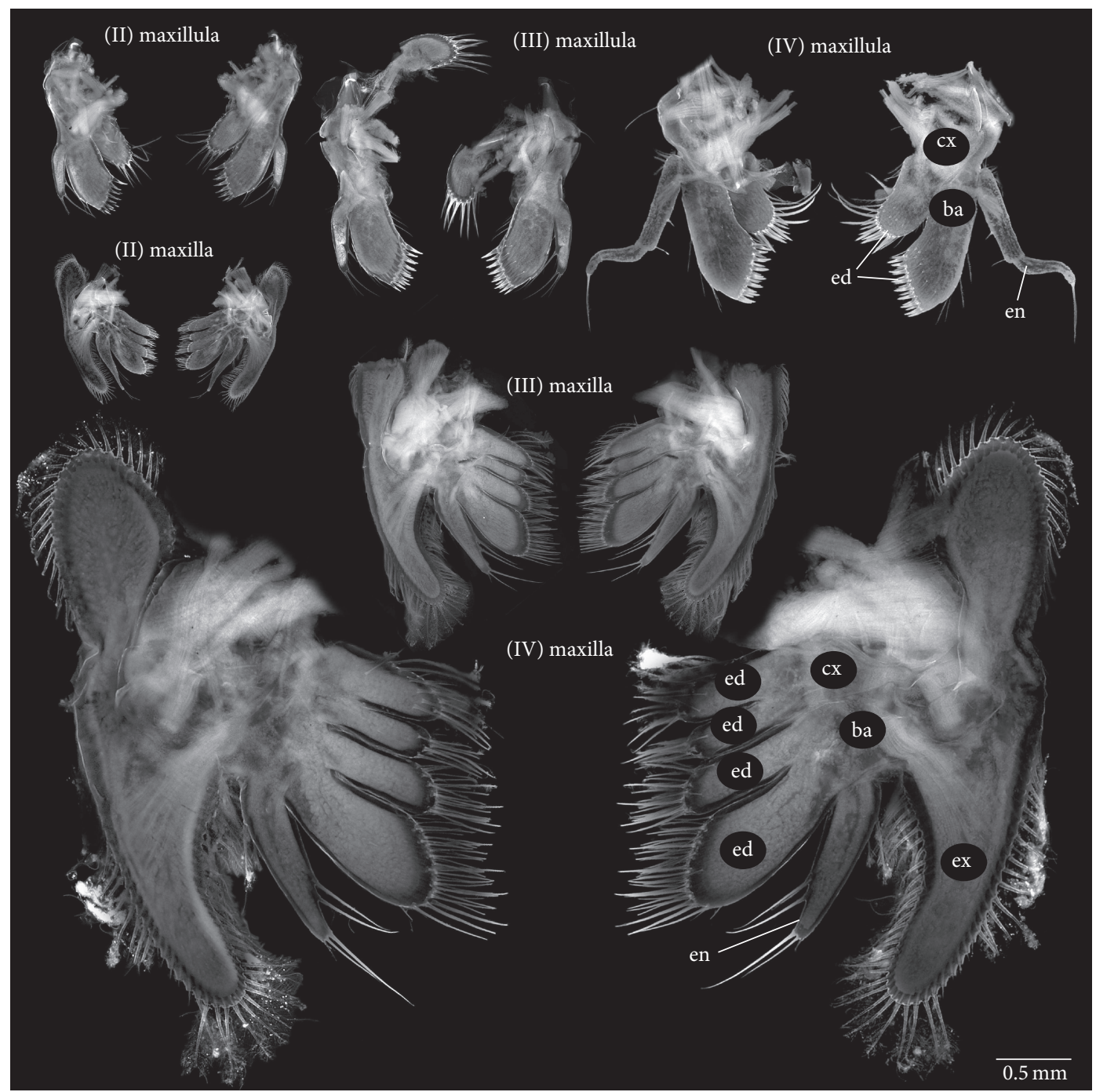

FIGURE 5: Maxillula and maxilla of larval stages (II) to (IV) of Homarus gammarus. Right appendage in anterior (left) and posterior (right) view, besides (II) maxillula, which is a left one flipped. Labeling only given in one instance due to the similarity of the structures throughout all stages. ba = basipod; $\mathrm{cx}=$ coxa; $\mathrm{ed}$ = endite; $\mathrm{en}=$ endopod; $\mathrm{ex}=$ exopod.

which is formed by the articulation of element 5 (dactylus) against an outgrowth of element 4 (propodus). Podobranch gill arising from coxa. Stage (II): endopod with trapezoidal (in anterior view) element 1 (ischium). Element 2 (merus) three times as long as ischium, Element 3 (carpus) slightly larger than element 1. Element 4 (propodus) twice the length of the carpus, twice as long as wide. Exopod welldeveloped, reaching to endopod element 3 (carpus). Stage (III): endopod has gained length, and exopod shows no further development, reaching now to endopod element 2 (merus). Stage (IV): endopod has gained significantly more length, element 2 (merus) has 2.4-fold its length, element 4 (propodus) doubled. Exopod reduced to a small (bright) vestigial structure.

Appendage of 10th Postocular Segment (5th Thoracopod). (Figure 8) All stages: consisting of protopod with coxa and basipod from the latter arise endopod and exopod. Endopod with five elements (ischium, merus, carpus, propodus, and dactylus). Distal part of this appendage is modified to a slender claw which is formed by the articulation of element 5 (dactylus) against an outgrowth of element 4 (propodus). Podobranch gill arising from coxa. Stage (II): endopod element 1 (ischium) convex tetragonal. Element 2 (merus) elongated rectangular, twice the length of element 1 . Element 3 (carpus) slightly larger than element 1 . Element 4 (propodus) twice as long as element 3. Exopod well-developed, reaching to endopod element 4. Stage (III): endopod has gained length, and exopod shows no further development reaching now to element 3. Stage (IV): endopod has gained more length, element 2 (merus) has 2.3-fold length and 4 (propodus) doubled its length (in comparison to stage (III)). Exopod reduced to a small (bright) vestigial structure.

Appendage of 11th Postocular Segment (6th Thoracopod). (Figure 8) All stages: consisting of protopod with coxa and 


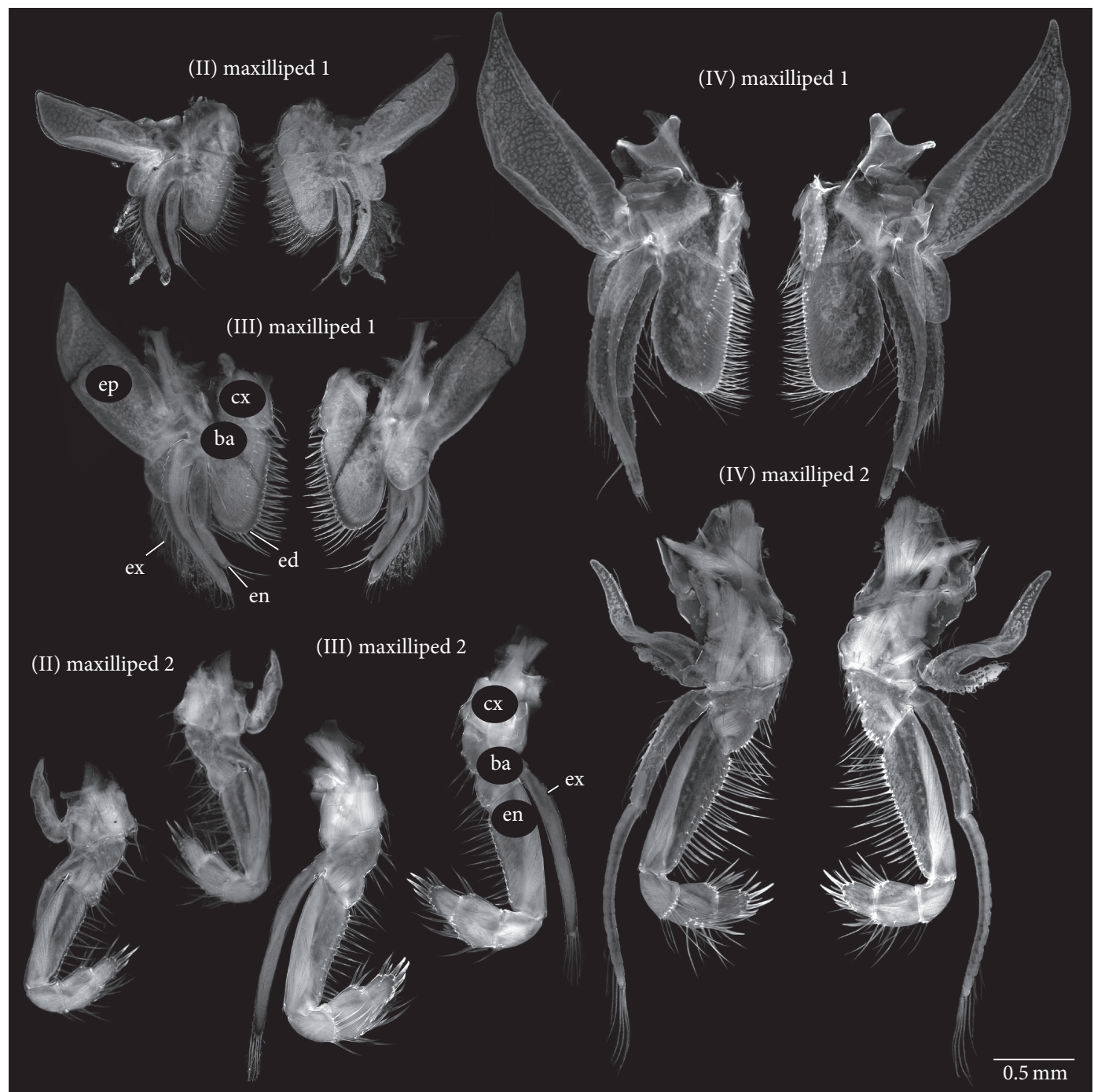

FIGURE 6: Maxilliped 1 and 2 of larval stages (II) to (IV) of Homarus gammarus. Right appendage in anterior (left) and posterior (right) view, besides (III) maxilliped 1 and (II) maxilliped 2, which are left ones flipped. Labeling only given in one instance due to the similarity of the structures throughout all stages. ba = basipod; $\mathrm{cx}=$ coxa; $\mathrm{ed}=$ endite; $\mathrm{en}=$ endopod; ep = epipod; ex = exopod.

basipod from the latter arise endopod and exopod. Endopod with five elements (ischium, merus, carpus, propodus, and dactylus). Distal part of this appendage is modified to a slender claw which is formed by the articulation of the element 5 (dactylus) against an outgrowth of element 4 (propodus). Podobranch gill arising from coxa. Stage (IV): endopod has gained more length, element 2 (merus) has 2.4fold length, element 4 (propodus) almost doubled. Exopod reduced to a small (bright) vestigial structure.

Appendage of 12th Postocular Segment (7th Thoracopod). (Figure 9) All stages: consisting of protopod with coxa and basipod from the latter arise endopod and exopod. Endopod with five elements (ischium, merus, carpus, propodus, and dactylus). Podobranch gill arising from coxa. Stage (II): endopod element 1 (ischium) convex tetragonal. Element 2 (merus) elongated rectangular, twice the length of element 1. Element 3 (carpus) of same size as element 1. Element 4 (propodus) twice as long as element 3. Element 5 (dactylus) sickle-shaped. Exopod well-developed, reaching to half of endopod element 4. Stage (III): endopod has gained length, around a third longer mainly caused by elongation of merus; exopod shows no further development. Stage (IV): endopod has gained more length, element 2 (merus) has 2.6-fold length and 4 (propodus) doubled (in comparison to stage (III)). Exopod reduced to a small (bright) vestigial structure.

Appendage of 13th Postocular Segment (8th Thoracopod). (Figure 9) All stages: consisting of protopod with coxa and basipod from the latter arise endopod and exopod. Endopod with five elements (ischium, merus, carpus, propodus, and dactylus). Podobranch gill arising from coxa. Stage (IV): endopod has gained more length, element 2 (merus) has 2.3 -fold length and 4 (propodus) doubled in its length (in comparison to stage (III)). Exopod reduced to a small (bright) vestigial structure. 


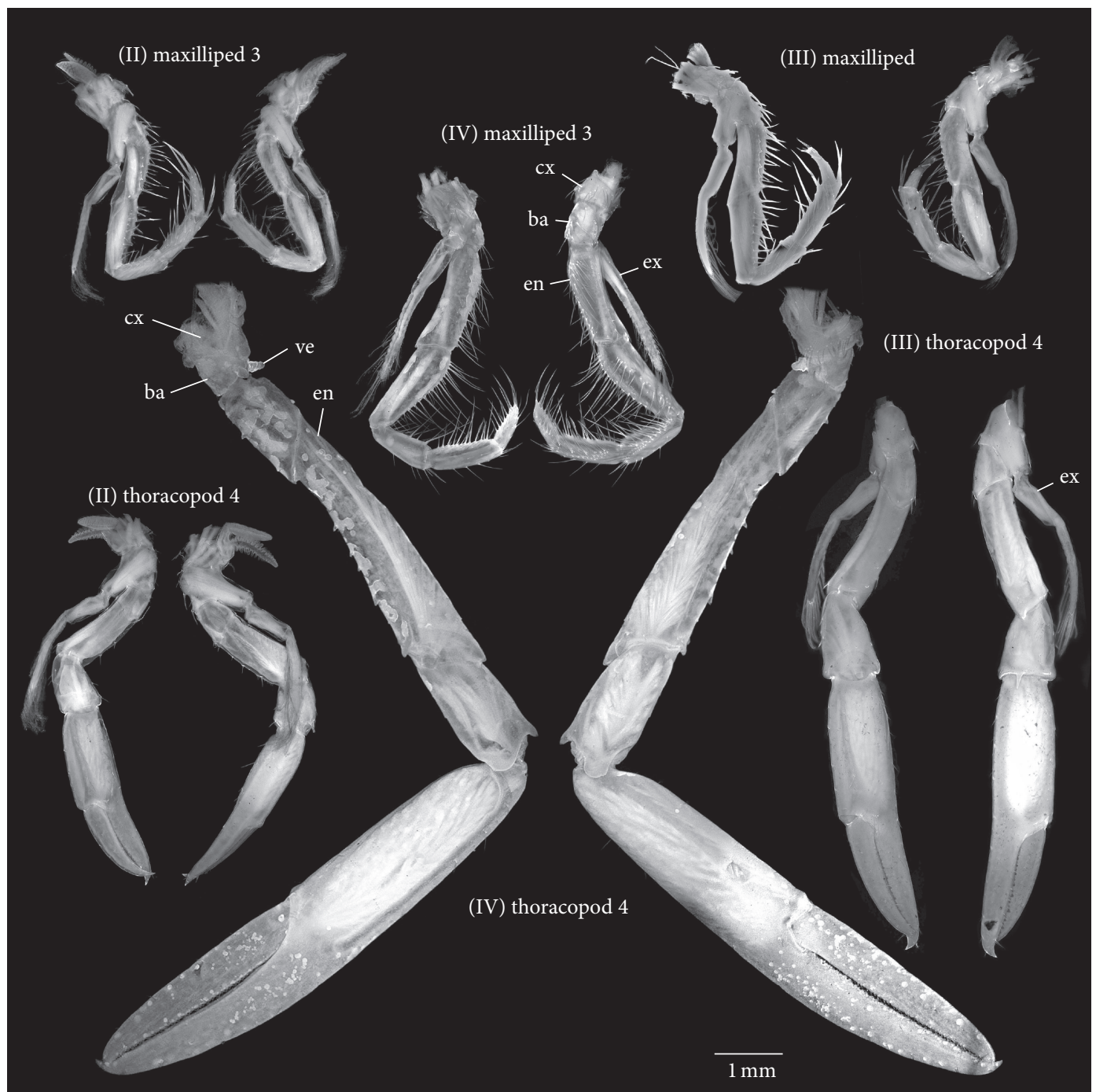

FIGURE 7: Maxilliped 3 and thoracopod 4 of larval stages (II) to (IV) of Homarus gammarus. Right appendage in anterior (left) and posterior (right) view, besides (II) maxilliped 3, (III) maxilliped 3, and (III) thoracopod 4, which are left ones flipped. Labeling only given in one instance due to the similarity of the structures throughout all stages. $\mathrm{ba}=$ basipod; $\mathrm{cx}=\mathrm{coxa}$; en = endopod; ex = exopod; ve = vestigial exopod.

Appendage of 14th Postocular Segment (1st Pleopod). Not found, not documented. This appendage is rather small in the adult; therefore its absence here is not surprising.

Appendage of 15th Postocular Segment (2nd Pleopod). (Figure 10) All stages: with basipod, endopod, and exopod. Endopod and exopod subsimilar, more or less paddleshaped. Stage (II): tiny, simple, stout appearance, without setae. Stage (III): slightly larger more definite shape, now armed with setae. Stage (IV): pronounced size increase, setae now significantly longer.

Appendage of 16th Postocular Segment (3rd Pleopod). (Figure 10) All stages: with basipod, endopod, and exopod. Endopod and exopod subsimilar, more or less paddleshaped. Stage (II): tiny, simple, stout appearance, without setae. Stage (III): slightly larger more definite shape, now armed with setae. Stage (IV): pronounced size increase, setae now significantly longer.
Appendage of 17th Postocular Segment (4th Pleopod). (Figure 10) All stages: with basipod, endopod, and exopod. Endopod and exopod subsimilar, more or less paddleshaped. Stage (II): tiny, simple, stout appearance, without setae. Stage (III): slightly larger more definite shape, now armed with setae. Stage (IV): pronounced size increase, setae now significantly longer.

Appendage of 18th Postocular Segment (5th Pleopod). (Figure 10) All stages: with basipod, endopod, and exopod. Endopod and exopod subsimilar, more or less paddleshaped. Stage (II): tiny, simple, stout appearance, without setae. Stage (III): slightly larger more definite shape, now armed with setae. Stage (IV): pronounced size increase, setae now significantly longer.

Appendage of 19th Postocular Segment (6th Pleopod; Uropod). (Figure 10) Stage (II): absent; initial uropods of the next stage can be seen under the cuticle. Stage (III): present, 


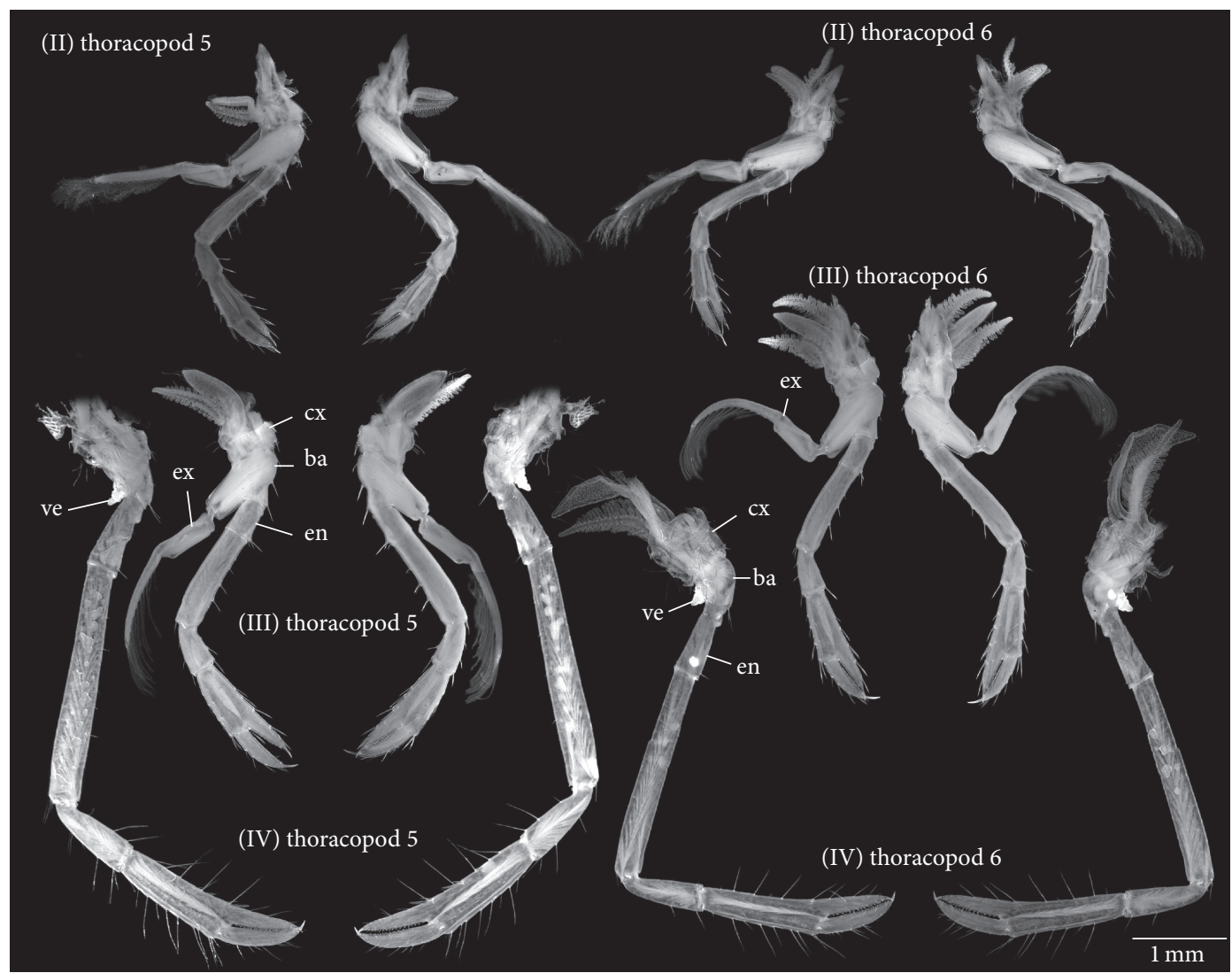

FIGURE 8: Thoracopods 5 and 6 of larval stages (II) to (IV) of Homarus gammarus. Right appendage in anterior (left) and posterior (right) view, besides (IV) thoracopod 5, (III) thoracopod 6, and (IV) thoracopod 6, which are left ones flipped. Labeling only given in one instance due to the similarity of the structures throughout all stages. $\mathrm{ba}=$ basipod; $\mathrm{cx}=$ coxa; $\mathrm{en}=$ endopod; ex = exopod; ve = vestigial exopod.

with basipod, endopod, and exopod. Endopod and exopod subsimilar, more or less paddle-shaped, small, clearly shorter than telson, armed with setae. Exopod continuous, without diaresis. Stage (IV): well developed uropods of almost the same length as telson, setae significantly longer, exopod now with pronounced diaresis.

Telson. (Figure 11) All stages: forming tailfan together with uropods (from stage (III) on) and bears anus ventrally. Stages (II) and (III): telson trapezoidal in dorsal view with straight edges, with lateroterminal spines and a central distal spine. Stage (IV): lateroterminal spines smaller; distal edge no longer straight but convexly curved. Central spine absent, distal margin armed with numerous setae.

3.2. Summary of Observed Features. Generally the size increases from stage to stage. We will summarize here some important morphological changes. As a note, each larva shows the new "inner" exoskeleton under the current one, already prepared for the next moult (e.g., uropods in stage (II) see Figure 1; see also examples in $[36,38])$. Yet, as this exoskeleton is partly "folded" to fit into the smaller skin this is of limited value for inferring morphological information; hence, these details are not described here.

The rostrum of stage (II) extends planar, whereas in stage (III) (Figure 3 ) it is equipped with incipient spines and already curved upwards at the front. Therefore it is formed like that of stage (IV) except for sharper spines.

The antennula (Figure 3) shows a pronounced difference in shape from stage (III) to stage (IV). The scale-like outer flagellum becomes narrower and both flagella become subdivided into articles. The scale-like flagellum possesses aesthetascs from early stages on; the larva possesses therefore the ability to scent, but a sensory function of the antennula cannot be assumed before stage (IV).

The antenna length clearly differs between stages (II) and (III). Yet, the gain in length is even more pronounced towards stage (IV). In some specimens, the antenna is not as elongate as in others (Figure 11).

The mouthparts (Figures 4 and 5) show little change over the observed three stages. They are already developed early on. The same is true for the three maxillipeds (Figures 6 and 7). Hence, all six pairs of appendages related to the feeding apparatus are fully functional from early on. The maxillipeds show less size gain compared to the maxillula and maxilla.

The five following thoracopods appear to develop in concert, although the fourth thoracopod (Figure 7) contrasts from the other thoracopods. The whole appendage is enlarged in width and length, especially distal parts forming the claws. Also the exopod is slightly shorter than in the following appendages. In stage (II) the exopods of thoracopods five to 


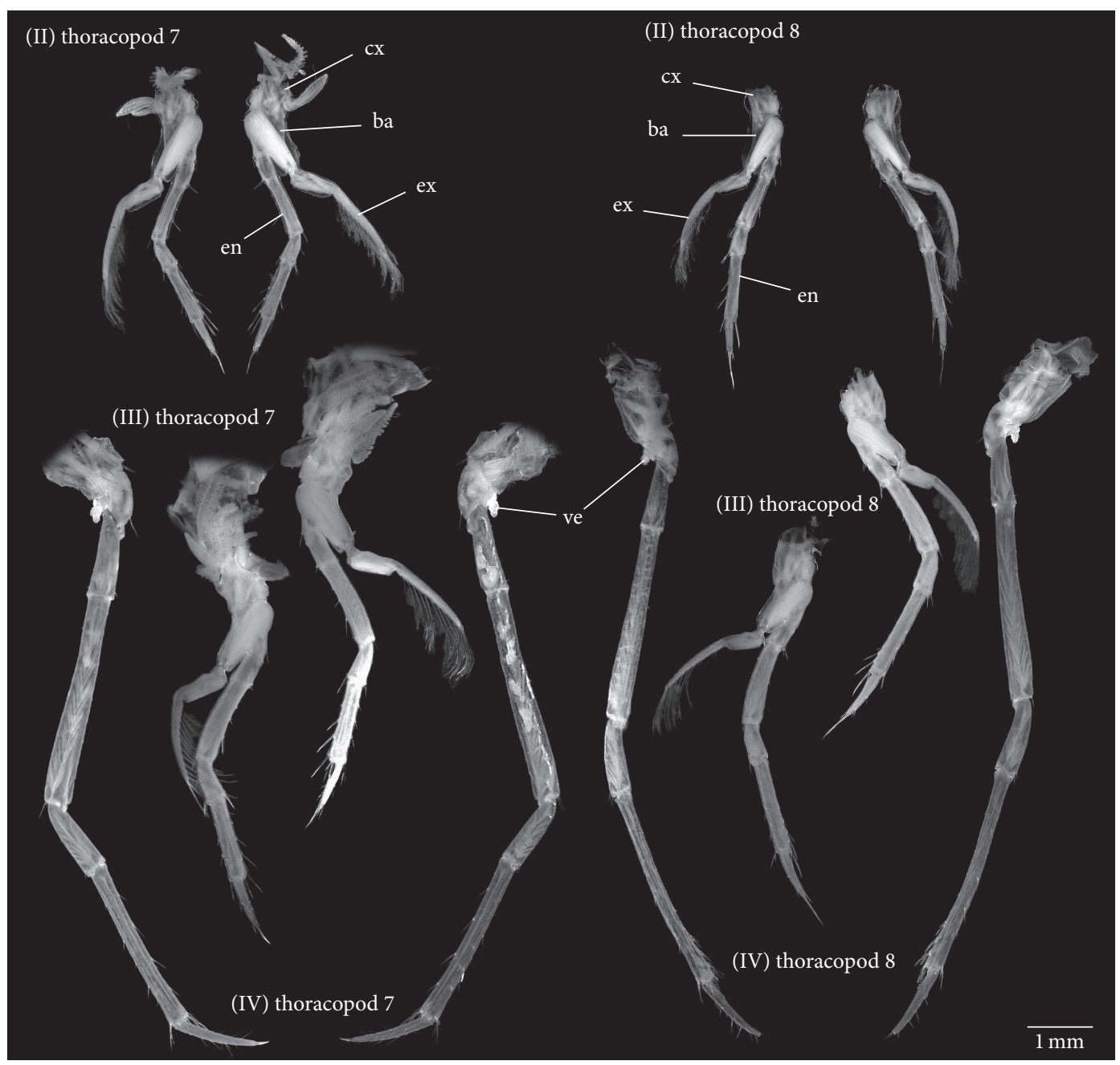

FIgURE 9: Thoracopods 7 and 8 of larval stages (II) to (IV) of Homarus gammarus. Right appendage in anterior (left) and posterior (right)

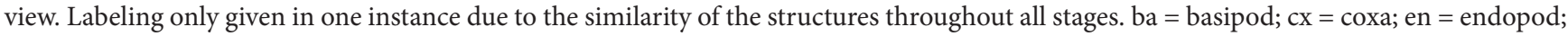
ex = exopod; ve = vestigial exopod.

eight reach endopod element 4, but in the fourth thoracopod the exopod stretches only over the second element. In stage (III) each exopod on the fifth to eighth thoracopod reaches almost the fourth endopod element (propodus) while in the fourth thoracopod it extends scarcely over the second element (merus). Exopods on thoracopods four to eight (Figures 7-9) become strongly reduced towards stage (IV), but tiny vestigial remains are still present. Also here is some variation; in some specimens the exopod remains are still quite large and include a socket and a distal region (Figure 11).

The insertion area of the fourth thoracopods seems to shift in stage (IV), but already during the previous larval stage (III) it is oriented further laterally and further in the front. In stage (I) the fourth thoracopod is directed downwards as the other extremities, but in stage (III) especially through the elongated merus a more frontal exposed position is already reached, resembling that of stage (IV).

The main axis (protopod and endopod) of the thoracopods changes little during larval development from stages (II) to (IV). Mainly a relative size gain is observed, but no pronounced change in shape. One notable exception is the shape of the claw of the fourth thoracopod, which is rather stout, simple, and distally rounded in stage (II), but more elongate from stage (III). The relative gain in size of the thoracopods results mainly from an elongation of merus and propodus in the moult form stages (III) to (IV).

The pleopods 2-5 (Figure 10) do hardly change in shape, although they can be considered to be still "immature" in stage (II), as their shape appears more rounded. The proportional size gain in stage (III) and especially stage (IV) is pronounced. Even more so is the size gain of the setal armature. Setae are absent in stage (II), are present, and at least are partly functional in stage (III), but significantly more elongated in stage (IV).

The tailfan (Figure 11) undergoes significant changes. In stage (II) no uropods are present and the telson possesses long lateral edges and a central tip. In stage (III) small uropods are developed already with long setae. In stage (IV) the telson gets an outer curve and now it bears long setae. The uropod has significantly gained size. 


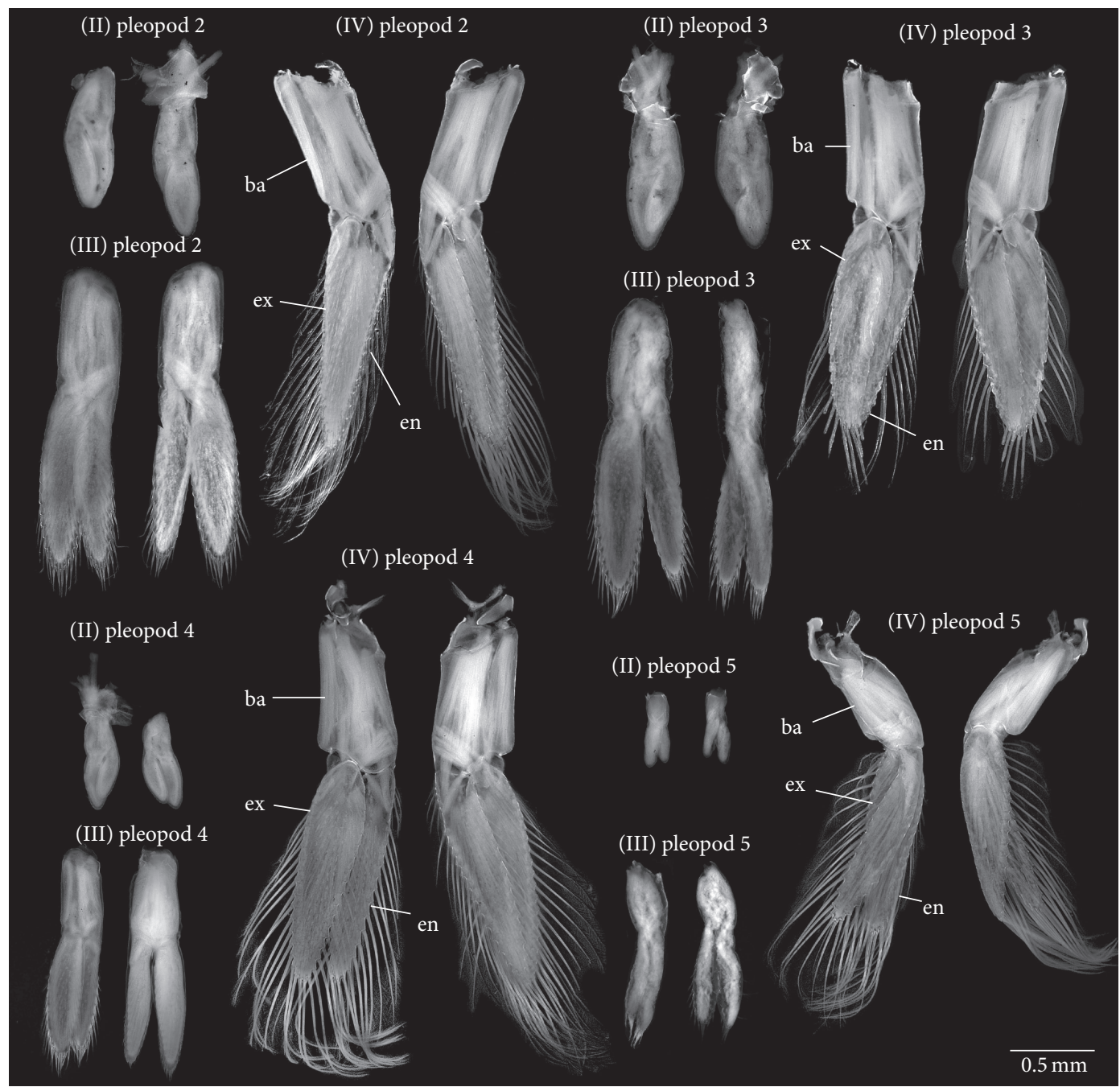

FIgURE 10: Pleopods 2-5 of larval stages (II) to (IV) of Homarus gammarus. Right appendage in anterior (left) and posterior (right) view, besides (IV) pleopod 5, which is left one flipped. Labeling only given in one instance due to the similarity of the structures throughout all stages. ba = basipod; en = endopod; ex = exopod.

\section{Discussion}

\subsection{Differences to Former Observations on Larvae of Homarus} gammarus. The larval stages of Homarus gammarus have been described before, and these observations are largely congruent with our observations. In contrast to our investigation, most of these former descriptions remain on an overview level (e.g., [39]). For example, the drawings in Carlberg et al. [40] are quite detailed, but without showing each appendage separately (although these depict hybrids of $H$. gammarus and $H$. americanus, the authors state that these are not different from larval stages of H. gammarus). These drawings appear, in observable details, similar to our observations. In other cases the comparison is more difficult. For example, in Neil et al. [41] the first three larval stages are drawn in a moderately detailed but stereotypic appearing way, while stage (IV) (megalopa) is drawn in a quite different style as it is magnified and provides more details. Such style differences make a comparison of ontogenetic changes more difficult.
As a slight intrastage variation was observed it is not surprising that there is some deviation in the observations of different authors. For example, the figure of stage (III) from Nichols and Lawton [42] displays the shifted fourth thoracopod, but not the already elongated second antenna that we have observed. In general, our observations are in concordance with earlier observations of larval stages of H. gammarus, although not necessarily with interpretations (see further below). Beyond that and unlike what is stated by Charmantier et al. [23], there are some recognizable differences in the ontogeny of Homarus gammarus that differ from $H$. americanus.

4.2. Differences between Larvae of Homarus gammarus and $H$. americanus. There are known differences between the larval stages of H. gammarus and H. americanus, discussed, for example, by Carlberg et al. [40]. The main differences noted are a larger size of the larvae and elongate claws in H. gammarus. This latter point must be partly questioned. When we compare stage (II) of the two species, both appear to 


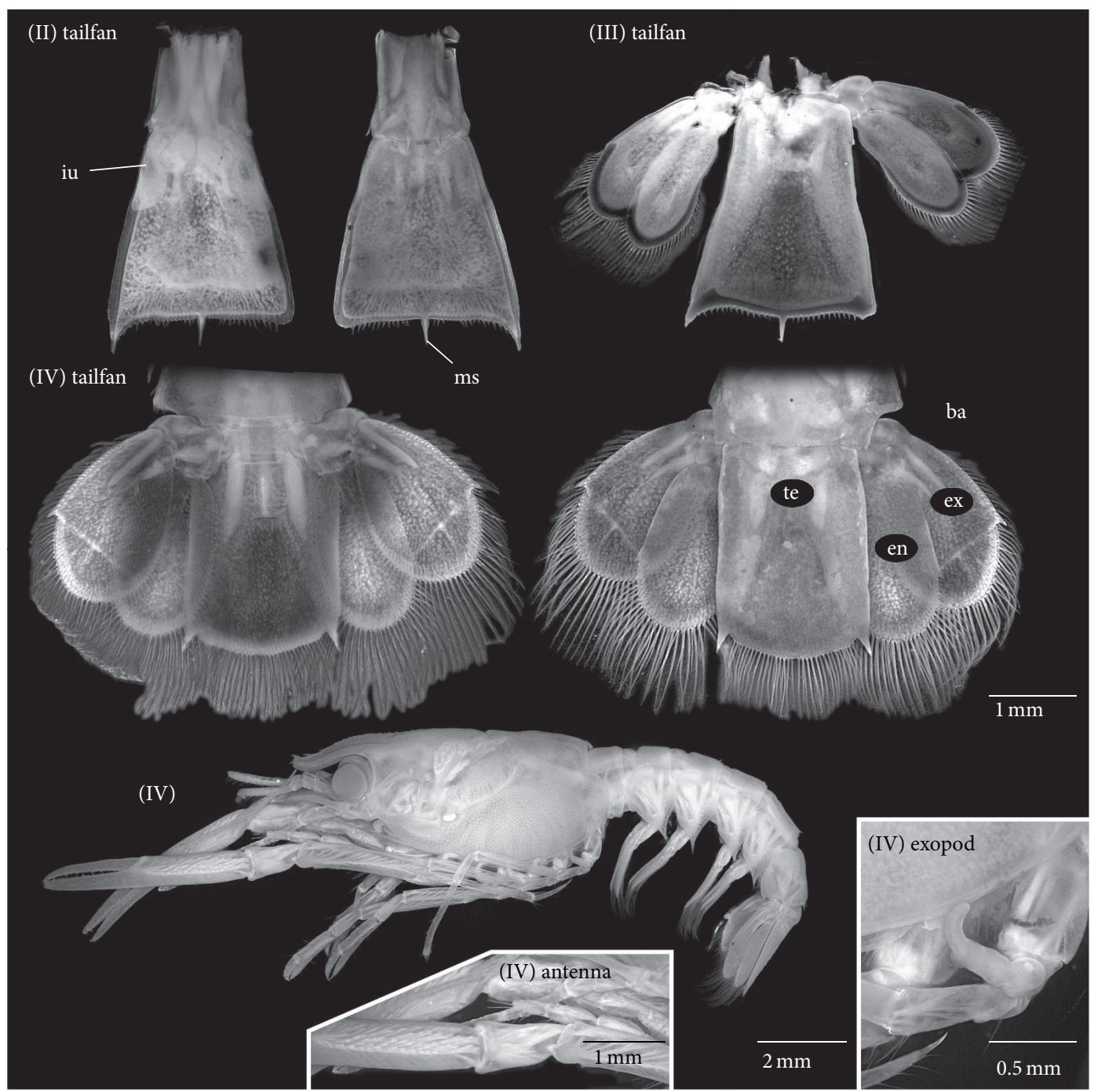

FIGURE 11: Tailfan of larval stages (II) to (IV) and variability of stage (IV) of Homarus gammarus. (II) Tailfan in ventral (left) and dorsal (right) view; note initial uropods visible through the cuticle. (III) Tailfan in dorsal view. (IV) Tailfan in ventral/anterior view (left) and dorsal/posterior view (right). Note the joint within the exopod paddle (diaresis) marked by arrow. (IV) Overview in lateral view; close-up on antenna which is significantly shorter than in the specimen in Figure 1; close-up on proximal region of thoracopods with a still quite long exopod remain. $\mathrm{ba}=$ basipod; $\mathrm{en}=$ endopod; $\mathrm{ex}=$ exopod; $\mathrm{iu}=$ initial uropod; $\mathrm{ms}=$ median spine; te $=$ telson .

be rather stout, simple, and distally rounded. The difference is notable in stage (III), in which the claw is still stouter in $H$. americanus (Figure 12), but elongate in H. gammarus (Figures 1 and 7). In stage (IV) the claw appears elongate in both species. In general, while stages (II) and (IV) indeed appear quite similar most differences appear to be expressed in stage (III). Yet, it is necessary to mention that there is also a certain degree of variation in stage (III) of H. gammarus. There are specimens in our material with a slightly more stout and distally more rounded, that is, less elongate claw. Additionally, the length of the flagellum of the (second) antenna varies slightly around $0.2 \mathrm{~mm}$ (Figure 2) and the rostrum is recurved.

To sum up, stage (III) in H. gammarus appears more advanced than that of $H$. americanus. The large claw is further developed and the rostrum is already recurved in
H. gammarus as it is in stage (IV) of both species. Another apparent difference is the length of the flagellum of the antennae; it is significantly longer (i.e., further developed) in H. gammarus in stage (III), while the lengths in stage (IV) of both species appear quite similar (although here is some variation; Figure 11). Also the overall appearance appears to be further developed in the larval stage (III) of H. gammarus.

Charmantier and Aiken [33] reported an intermediate stage in certain individuals of $H$. americanus. These forms had been known rarely in wild populations before, but the authors induced such intermediate stages artificially through eyestalk ablation. This procedure resulted in incomplete metamorphosis and produced a stage termed (IVa) (Figure 12) with an intermediate morphology between stages (III) and (IV). Under natural condition this intermediate stage appears to be triggered by unfavourable settling conditions [33], as the 


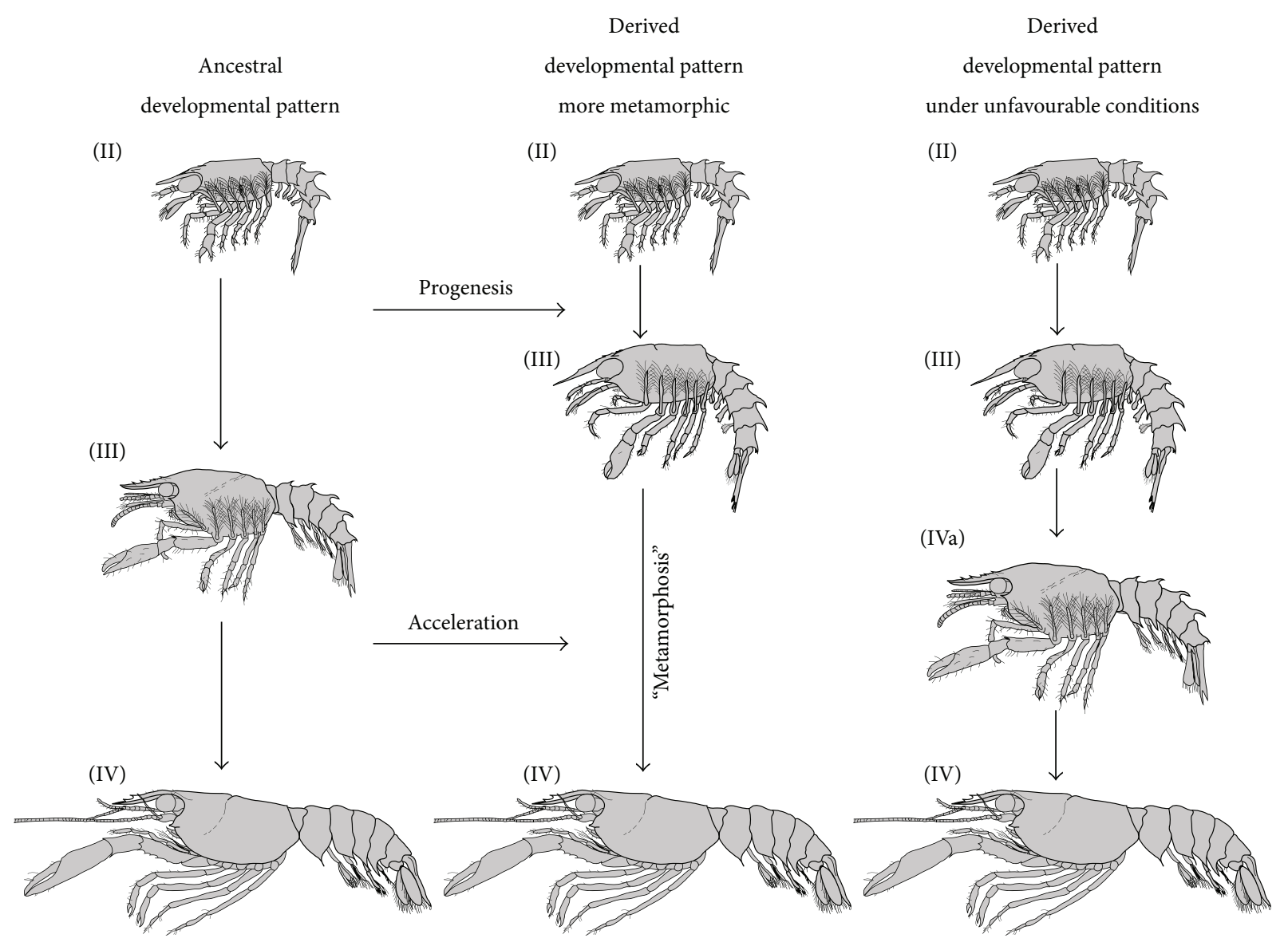

FIGURE 12: Evolutionary scenario for the changes in ontogeny in Homarus. Presumed ancestral developmental pattern as seen in H. gammarus (and hybrids of $H$. gammarus and $H$. americanus), with rather gradual developmental steps. Derived developmental pattern as seen in $H$. americanus; the stage (III) is less far developed than that in the ancestral pattern. Hence the developmental step from (II) to (III) is "shorter" and leads to a more juvenile appearing larva (III) $\rightarrow$ paedomorphosis. The larva was simply "stopped," as it is also slightly smaller $\rightarrow$ progenesis. The developmental step from (III) to (IV) on the other hand is now more pronounced, it appears more metamorphic, and this moult is often interpreted as a "metamorphosis." This type of heterochronic shift is a peramorphosis, more precise, and it represents a case of acceleration. All drawings modified by Charmantier et al. [23] and Charmantier and Aiken [33].

correct substrate appears to be the most important trigger for metamorphosis $[43,44]$. It is furthermore important to mention that later stages following this intermediate stage appear to remain unchanged. As all eye-stalkless stages finally moulted into normal stages, it seems that stress induces differences in the development of stage (III), but these do not perpetuate into the adult form in $H$. americanus.

In comparison with the drawings of Charmantier and Aiken [33] the larvae of stage (III) studied herein seem to correspond more to a stage (IVa) of $H$. americanus than to a stage (III) of the latter species. For example, the more elongate claw of the fourth thoracopod in our observations is rather equivalent to stage (IVa) than to stage (III) of $H$. americanus. Also the developmental degree of rostrum and antennal flagellum matches well stage (IVa) of H. americanus.

However, the observed telson morphology of $\mathrm{H}$. gammarus corresponds neither to stage (III) nor to stage (IVa) of $H$. americanus. In general the telson in $H$. gammarus seems to be advanced in development as that of stage (II) in $H$. gammarus resembles that of stage (III) in H. americanus.
Charmantier and Aiken [33] also mention the presence of intermediate stages in $H$. gammarus, based on literature data like their (IVa) in $H$. americanus. As we conclude that the morphology of stage (III) in H. gammarus is best compared to stage (IVa), this is partly surprising. One could conclude that all our stage (III) specimens are in fact (IVa) stages and we lack a true stage (III). This is unlikely to be the case. As Charmantier and Aiken [33] stated, this stage occurs only rarely or can be induced by eyestalk ablation. All our supposed stage (III) specimens look pretty much alike (Figures 1 and 2, despite the slight variation), they have eyes, and they are very similar to all reports of stage (III) larvae of $H$. gammarus in the literature. Hence we conclude that this morphology is indeed that of stage (III) and does not represent a stage (IVa). Therefore, the question arises: what do intermediate stages or early megalopas look like in $H$. gammarus? As we pointed out, stage (IV) shows a certain degree of variation including more "immature appearing" specimens, for example, with shorter antennae or still better developed exopods (Figure 11). 
4.3. Is There a Metamorphosis in Homarus gammarus? Metamorphosis is described as a rapid and drastic change of morphology during ontogeny (e.g., [4]). It is generally accepted that metamorphosis occurs at the fourth moult and therefore from stage (III) to stage (IV) in species of Homarus. The fourth stage is therefore often termed the postmetamorphic stage [16, 23]. Hadley [45] stated that stages (III) and (IV) differ in form and behavior. Morphologically this should be manifested in asymmetrical claws and a longer pleon [46]. Yet, other authors have pointed out that claw asymmetry does not develop before stage (V) [47] and also the relative length of the pleon does not increase in a single jump from stages (III) to (IV) but becomes already elongated from stages (III) to (IV) (Figure 1). Other reports focused on differences in body structure and behaviour, as stage (IV) animals swim forward by using their pleopods, seeking for the right substrate for settling for benthic life.

The above morphological modifications were not detected in the present study. Stage (III) resembles the following stage to a large degree (as pointed out above). Many body parts are developed early, such as the mouthparts, or changes occur more gradual, that is, in the similar amount of change from one stage to another. For example, the fourth thoracopods are brought more and more laterally and have shorter exopods before they become entirely reduced. This observation leads to the overall impression of a more gradual change instead of a radical change which is demanded for a metamorphosis. Still there is a rapid growth of certain structures: relative length gain of antennae, thoracopods, and pleopods are very apparent, but does a rapid size gain indicate a metamorphosis; that is, is this radical enough?

Regarding behavioral changes from stage (III) to stage (IV), the switch seems also to be quite less rapid than generally assumed, here, too, modification takes its time. Charmantier and Aiken [33] state that stage (IV) animals become progressively (sic!) more benthic, but this behavior is not fixed before stage (V). Also the feeding strategies are transitional at stage (IV). The animals can eat various organisms, such as marine worms, small crabs, sea urchins, and gastropods, but still retain the ability for filter-feeding on plankton [48]. Thus, although seemingly a radical change occurs in the way of life as stage (IV) settles into "a new ecological niche," the initial feeding strategy does not get lost while the new one is gained. Therefore also the feeding strategy displays no radical switch, but a progression. As J. T. Haug and C. Haug [4] have pointed out there can be no absolute criterion if an ontogenetic pathway is metamorphic or nonmetamorphic. It is only possible to compare two ontogenetic patterns and determine which one most closely resembles metamorphic.

So we can state that the morphological change from stage (III) to stage (IV) appears more metamorphic in $H$. americanus than in H. gammarus. But on the other hand, the morphological changes between stage (II) and stage (III) are less pronounced in H. americanus than in H. gammarus.

4.4. Evolution of Metamorphosis in Nephropid Lobsters. Compared to $H$. gammarus stage (III) H. americanus is at a different "position" between stage (II) and stage (IV)
(Figure 12). Therefore, we will discuss possible mechanisms of the evolution for such a difference. Could stage (IVa) in $H$. americanus be part of a more ancestral developmental pattern and was then evolutionarily skipped (as suggested for other species, e.g., in $[1,4])$ ? This seems unlikely, as other nephropid lobsters also have three zoeal stages (e.g., [22]); the total number of three might well represent an ancestral feature of the group and it seems unlikely that H. americanus first gained an additional stage and then lost it again. It seems more likely that we see a (doubled) heterochronic shift in $H$. americanus: the development of stage (III) seems slowed down; more precisely it is most likely truncated (progenesis), but that to stage (IV) is accelerated (acceleration). This combination of a paedomorphosis and a peramorphosis, that is, this shift leads to the impression that $H$. americanus, is more metamorphic than H. gammarus (Figure 12) but leaves stages (II) and (IV) virtually unchanged. The rarely occurring stage (IVa) seems to be a result of this larger developmental jump, making it necessary to make an intermediate moult under unfavourable conditions (Figure 12).

Also the moult to stage (IV) in Nephrops norvegicus appears more metamorphic than that of H. gammarus as the larvae of $N$. norvegicus possess floating spines as larval specialisations (e.g., $[5,39,49])$, which become reduced in the moult to the megalopa (see [4] for discussion of this mechanism in the context of metamorphosis). The more gradual pattern in H. gammarus and its unspecialised larval morphologies might well represent the ancestral developmental pattern for nephropid lobsters. Yet, such a conclusion demands a more extensive comparison including data on larval morphology for other species. It is noteworthy in this aspect that hybrids of $H$. americanus and $H$. gammarus possess larval morphologies as seen in H. gammarus. It has been argued in quite different animal groups, namely, sea urchins and starfish, that hybrids possess more ancestral types of larvae (e.g., [50,51]). Although such conclusions must remain preliminary (as there is no well-formulated concept for this type of conclusion) it could be seen as a support for the interpretation that the developmental pattern in H. gammarus is rather plesiomorphic.

As pointed out there seems to be a strong selective pressure favouring more metamorphic patterns over gradual ones $[4,52,53]$. In European lobsters the third larval phase is described as a critical period through which only $0.005 \%$ (estimated) of the individuals survive the planktic phase to reach the benthic phase [48]. Larvae often form large masses which are highly vulnerable to predation by schooling fish such as herring, cod, and filter feeders, for example, basking sharks. The fourth stage appears to have a higher survival rate as it exists out of reach of several pelagic predators. Considering the additional danger for the planktic larvae to drift away, it may be assumed that natural selection favours this period to be short.

Hence, the shift seen in H. americanus can be understood in this light. Its stage (III) more strongly resembles stage (II) and should thus be better adapted to life in the plankton. Stage (III) of H. gammarus already shows some character of stage (IV) with its adaptations to a later benthic life, while still living in the plankton. Such "mixed" stages should be 
strongly selected against [53]. Possibly, the larger egg size in $H$. gammarus could explain why it can afford to retain such a stage, while in $H$. americanus (with smaller eggs) the observed developmental shift occurred.

An important point to mention is the certain morphological variation, which appears to be present in all larval stages at least of Homarus. Variation is one of the prerequisites for evolution to act on. Hence this type of variation combined with the right selective pressures enables ontogenetic shifts in the here observed ways.

4.5. Consequences for Our Understanding of Metamorphosis in General. J. T. Haug and C. Haug [4] argued that two effects would lead to the evolution of metamorphosis:

(1) evolution of specialized larval characters that are absent in the adult, as they increase the morphological disparity between early and late developmental stages, and

(2) the evolution of developmental jumps, for example, by skipping of intermediate stages, which leads to a more rapid change of morphology.

In the case discussed here the effect is quite different. Only the morphological degree of development of a single stage is shifted. Thus, such a combined retention and acceleration affecting only a single stage, as in $H$. americanus, also lead to a more metamorphic pattern as it increases the morphological disparity between two stages (in this case (III) and (IV)).

Yet, here we encounter another terminological issue. While indeed the morphological change at the transition from stages (III) to (IV) is clearly more pronounced in $H$. americanus than in H. gammarus, it is still significantly less pronounced than in other decapods. The change from last phyllosoma stage to nisto or puerulus in slipper lobsters and spiny lobsters is the most drastic example $([13-15,53,54])$ but also the transition from zoea to megalopa in brachyuran crabs (e.g., [55-59]) or from zoea to glaucothoe (or megalopa) in anomalans (e.g., [60-64]) clearly involve a much more pronounced change of morphology.

Nephropid lobsters may well represent an interesting example at the "lower end" of the spectrum of metamorphosis, as a kind of opposite to achelate lobsters, which are at the "high end" [53]. The especially short larval sequence makes investigations comparably simple. The variation of the morphology of larval stages, but also the possibility of in-group species to reduce the number of larval stages, all indicate that nephropids are a good candidate group for studying the evolution of metamorphosis. As pointed out above, a more extensive taxon sampling, that is, developmental data of more nephropid species, will be necessary.

\section{Conclusion}

This work primarily displays the morphological changes of (zoea-)larval stages to "postlarva" (megalopa) of Homarus gammarus with up-to-date imaging methods.
We show that

(i) larval stage (III) displays a more advanced developmental state that lies (developmentally) closer to stage (IV) in Homarus gammarus than in H. americanus;

(ii) the moult of stage (III) to stage (IV) has a less drastic change in H. gammarus; that is, the developmental pattern in this species is more gradual;

(iii) in nephropid lobsters, comparably small changes in developmental timing lead to recognizable morphological changes.

\section{Conflict of Interests}

The authors declare that there is no conflict of interests regarding the publication of this paper.

\section{Acknowledgments}

Numerous institutions and people supported the present project, which are all thanked here. Isabel Schmalenbach, from the marine station in Helgoland, kindly provided the material. The authors would like to thank Stefan Friedrich, Zoological State Collection Munich, for curating the material. The project is part of Joachim T. Haug's project "Malacostracan Palaeo-Evo-Devo" kindly funded by the German Research Foundation (DFG) under Ha 6300/3-1. The authors thank J. Matthias Starck, Munich, for his support. Carolin Haug, Munich, and Joel W. Martin, Los Angeles, gave useful comments on an older version of this paper. The authors also thank all people providing free or low cost software, which were also partly used here, such as Combine ZM/ZP, Microsoft Image Composite Editor, GIMP, OpenOffice.

\section{References}

[1] D. Walossek, "The upper Cambrian Rehbachiella kinnekullensis and the phylogeny of Branchiopoda and Crustacea," Fossils Strata, vol. 32, pp. 1-202, 1993.

[2] J. T. Haug, A. Maas, and D. Waloszek, "Henningsmoenicaris scutula, Sandtorpia vestrogothiensis gen. et sp. nov. and heterochronic events in early crustacean evolution," Earth and Environmental Science Transactions of the Royal Society of Edinburgh, vol. 100, pp. 311-350, 2010.

[3] J. T. Haug, D. Waloszek, C. Haug, and A. Maas, "Highlevel phylogenetic analysis using developmental sequences: the Cambrian Martinssonia elongata, Musacaris gerdgeyeri gen. et sp. nov. and their position in early crustacean evolution," Arthropod Structure \& Development, vol. 39, pp. 154-173, 2010.

[4] J. T. Haug and C. Haug, "An unusual fossil larva, the ontogeny of Achelatan lobsters, and the evolution of metamorphosis," Bulletin of Geosciences, vol. 88, no. 1, pp. 195-206, 2013.

[5] R. Gurney, Larvae of Decapod Crustacea, Ray Society, London, UK, 1942.

[6] D. I. Williamson, "Names of larvae in the Decapoda and Euphausiacea," Crustaceana, vol. 16, no. 2, pp. 210-213, 1969.

[7] P. D. Shield, "Larval development of the caridean shrimp, Hippolyte pleuracanthus (Stimpson), reared in the laboratory," Estuaries, vol. 1, no. 1, pp. 1-16, 1978. 
[8] C. J. Walsh, "Larval development of Paratya australiensis Kemp, 1917 (Decapoda: Caridea: Atyidae), reared in the laboratory, with comparisons of fecundity and egg and larval size between estuarine and riverine environments," Journal of Crustacean Biology, vol. 13, no. 3, pp. 456-480, 1993.

[9] J. Y. Hoi and H. K. Chang, "Zoeal stages of Heptacarpus futilirostris (Decapoda, Caridea, Hippolytidae) reared in the laboratory," Crustaceana, vol. 78, no. 5, pp. 543-564, 2005.

[10] G. Guerao and J. A. Cuesta, "Caridea," in Atlas of Crustacean Larvae, J. W. Martin, J. Olesen, and J. T. Høeg, Eds., pp. 250-255, Johns Hopkins University Press, Baltimore, Md, USA, 2014.

[11] J. W. Martin, M. M. Criales, and A. dos Santos, "Dendrobranchiata," in Atlas of Crustacean Larvae, J. W. Martin, J. Olesen, and J. T. Høeg, Eds., pp. 235-242, Johns Hopkins University Press, Baltimore, Md, USA, 2014.

[12] J. W. Goy and A. J. Provenzano, "Larval development of the rare burrowing mud shrimp Naushonia crangonoides Kingsley (Decapoda: Thalassinidea; Laomediidae)," Biological Bulletin, vol. 154, no. 2, pp. 241-261, 1978.

[13] B. Marinovic, J. W. T. J. Lemmens, and B. Knott, "Larval development of Ibacus peronii Leach (Decapoda: Scyllaridae) under laboratory conditions," Journal of Crustacean Biology, vol. 14, no. 1, pp. 80-96, 1994.

[14] S. Mikami and J. G. Greenwood, "Complete development and comparative morphology of larval Thenus orientalis and Thenus sp. (Decapoda: Scyllaridae) reared in the laboratory," Journal of Crustacean Biology, vol. 17, no. 2, pp. 289-308, 1997.

[15] W. R. Webber and J. D. Booth, "Larval stages, developmental ecology, and distribution of Scyllarus sp. Z (probably Scyllarus aoteanus Powell, 1949) (Decapoda: Scyllaridae)," New Zealand Journal of Marine and Freshwater Research, vol. 35, no. 5, pp. 1025-1056, 2001.

[16] F. Mehrtens, Untersuchungen zu den Entwicklungsbedingungen des Europäischen Hummers Homarus gammarus bei Helgoland in Freiland und Labor [Ph.D. thesis], University Hamburg, 2011.

[17] A. W. Harvey, J. W. Martin, and R. Wetzer, "Phylum Arthropoda: Crustacea," in Atlas of Marine Invertebrate Larvae, C. M. Young, Ed., pp. 337-369, Academic Press, London, UK, 2002.

[18] G. Gerlach and J. Artema, "The use of chemical cues in habitat recognition and settlement," in Chemical Ecology in Aquatic Systems, C. Brönmark and L.-A. Hansson, Eds., pp. 72-89, Oxford University Press, Oxford, UK, 2012.

[19] P. A. Prodöhl, K. E. Jørstad, A. Triantafyllidis, V. Katsares, and C. Triantaphyllidis, "European lobster-Homarus gammarus," in Genetic Impact of Aquaculture Activities on Native Populations. Final Scientific Report, T. Svåsand, D. Crosetti, E. GarcíaVázquez, and E. Verspoor, Eds., pp. 91-98, 2006.

[20] S. Mikami and A. V. Kuballa, "Factors important in larval and postlarval molting, growth, and rearing," in The Biology and Fisheries of the Slipper Lobster, K. L. Lavelli and E. Spanier, Eds., pp. 91-110, CRC Press, Boca Raton, Fla, USA, 2007.

[21] J. W. Goy, “Astacidea," in Atlas of Crustacean Larvae, J. W. Martin, J. Olesen, and J. T. Høeg, Eds., pp. 256-262, Johns Hopkins University Press, Baltimore, Md, USA, 2014.

[22] K. Okamoto, "Japanese nephropid lobster Metanephrops japonicus lacks zoeal stage," Fisheries Science, vol. 74, no. 1, pp. 98-103, 2008.

[23] G. Charmantier, M. Charmantier-Daures, and D. E. Aiken, "Metamorphosis in the lobster Homarus (Decapoda): a review," Journal of Crustacean Biology, vol. 11, pp. 481-495, 1991.
[24] D. E. Aiken, "Molting and growth," in The Biology and Management of Lobsters: Physiology and Behavior, J. S. Cobb and B. F. Phillips, Eds., vol. 1, pp. 91-155, Academic Press, New York, NY, USA, 1980.

[25] H. C. Williamson, "A contribution to the life history of the lobster (Homarus vulgaris)," 23rd Annual Report of the Fisheries Board of Scotland, 1904, Part 3, 1905.

[26] W. Templeman, "Fourth stage larvae of Homarus americanus intermediate in form between normal third and fourth stages," Journal of the Biological Board of Canada, vol. 2, no. 4, pp. 349354, 1936.

[27] R. Gurney, "Notes on some decapod Crustacea from the Red Sea I. The genus Processa. II. The larvae of Upogebia savignyi, Strahl," Proceedings of the Zoological Society of London, pp. 85101, 1937.

[28] R. H. Gore, "Molting and growth in decapod larvae," in Crustacean Issues 2: Larval Growth, A. M. Wenner, Ed., pp. 165, Balkema, Rotterdam, The Netherlands, 1985.

[29] D. F. Villamar and G. J. Brusca, "Variation in the larval development of Crangon nigricauda (Decapoda: Caridea), with notes on larval morphology and behavior," Journal of Crustacean Biology, vol. 8, no. 3, pp. 410-419, 1988.

[30] C. Haug, J. T. Haug, and D. Waloszek, "Morphology and ontogeny of the Upper Jurassic mantis shrimp Spinosculda ehrlichi n. gen. n. sp. from southern Germany," Palaeodiversity, vol. 2, pp. 111-118, 2009.

[31] J. T. Haug, C. Haug, D. Waloszek, A. Maas, M. Wulf, and G. Schweigert, "Development in Mesozoic scyllarids and implications for the evolution of Achelata (Reptantia, Decapoda, Crustacea)," Palaeodiversity, vol. 2, pp. 97-110, 2009.

[32] J. T. Haug, C. Haug, D. Waloszek, and G. Schweigert, "The importance of lithographic limestones for revealing ontogenies in fossil crustaceans," Swiss Journal of Geosciences, vol. 104, supplement 1, pp. S85-S98, 2011.

[33] G. Charmantier and D. E. Aiken, "Intermediate larval and postlarval stages of Homarus americanus," Journal of Crustacean Biology, vol. 7, pp. 525-535, 1987.

[34] C. Haug, J. T. Haug, D. Waloszek, A. Maas, R. Frattigiani, and S. Liebau, "New methods to document fossils from lithographic limestones of southern Germany and Lebanon," Palaeontologia Electronica, vol. 12, no. 3, article 6T, 12 pages, 2009.

[35] J. T. Haug, C. Haug, and M. Ehrlich, "First fossil stomatopod larva (Arthropoda: Crustacea) and a new way of documenting Solnhofen fossils (Upper Jurassic, Southern Germany)," Palaeodiversity, vol. 1, pp. 103-109, 2008.

[36] J. T. Haug, C. Haug, V. Kutschera et al., "Autofluorescence imaging, an excellent tool for comparative morphology," Journal of Microscopy, vol. 244, no. 3, pp. 259-272, 2011.

[37] C. Haug, K. R. Shannon, T. Nyborg, and F. J. Vega, "Isolated mantis shrimp dactyli from the Pliocene of North Carolina and their bearing on the history of Stomatopoda," Bolétin de la Sociedad Geológica Mexicana, vol. 65, no. 2, pp. 273-284, 2013.

[38] C. Haug, G. Mayer, V. Kutschera, D. Waloszek, A. Maas, and J. T. Haug, "Imaging and documenting gammarideans," International Journal of Zoology, vol. 2011, Article ID 380829, 9 pages, 2011.

[39] D. I. Williamson, “Decapoda, Larvae, VIII,” Fich. Ident. Zooplancton, vol. 167-168, pp. 1-8, 1983.

[40] J. M. Carlberg, J. C. Van Olst, and R. F. Ford, "A comparison of larval and juvenile stages of the lobsters Homarus americanus, Homarus gammarus, and their hybrid," Proceedings of the 
Annual Meeting-World Mariculture Society, vol. 9, no. 1-4, pp. 109-122, 1978.

[41] D. M. Neil, D. L. Macmillan, R. M. Robertson, and M. S. Laverack, "The structure and function of thoracic exopodites in the larvae of the lobster Homarus gammarus (L.)," Philosophical Transactions of the Royal Society B: Biological Sciences, vol. 274, no. 929, pp. 53-68, 1976.

[42] J. H. Nichols and P. L. Lawton, "Occurrence of larval stages of the lobster, Homarus gammarus (Linnaeus 1758) off the northeastern coast of England in 1976," J Cons Int Explor Mer, vol. 38, pp. 234-243, 1978.

[43] M. Walther, Krebstiere (Crustacea)_Biologie, Vorkommen, Haltung und Erkrankungen, sowie ihre Bedeutung als Zootierobjekte und Lebensmittelressourcen-Eine Literaturstudie [Dissertation], University of Giessen, Giessen, Germany, 2008.

[44] L. Botero and J. Atema, "Behaviour and substrate selection during larval settling in the lobster Homarus americanus," Journal of Crustacean Biology, vol. 2, no. 1, pp. 59-69, 1982.

[45] P. B. Hadley, "Observations on some influences of light upon the larval and early adolescent stages of Homarus americanus," Preliminary Report: 36th Annual Report of the Rhode Island Commission of Inland Fish 24, 1906.

[46] F. Nicosia and K. Lavalli, "Homarid lobster hatcheries: their history and role in research, management, and aquaculture," Marine Fisheries Review, vol. 61, no. 2, pp. 1-57, 1999.

[47] C. K. Govind and J. Pearce, "Critical period for determining claw asymmetry in developing lobsters," Journal of Experimental Zoology, vol. 249, no. 1, pp. 31-35, 1989.

[48] National Lobster Hatchery, "Biology of the European lobster, Homarus gammarus," 2014, http://www.nationallobsterhatchery.co.uk/whats-it-all-about/education/lobster-biology/.

[49] R. S. M. Smith, The biology of larval and juvenile Nephrops norvegicus (L.) in the Firth of Clyde [Ph.D. thesis], University of Glasgow, Glasgow, UK, 1987.

[50] E. C. Raff, E. M. Popodi, B. J. Sly, F. R. Turner, J. T. Villinski, and R. A. Raff, "A novel ontogenetic pathway in hybrid embryos between species with different modes of development," Development, vol. 126, no. 9, pp. 1937-1945, 1999.

[51] K. Wakabayashi, M. Komatsu, M. Murakami, I. Hori, and T. Takegami, "Morphology and gene analysis of hybrids between two congeneric sea stars with different modes of development," Biological Bulletin, vol. 215, no. 1, pp. 89-97, 2008.

[52] B. Ebenman, "Evolution in organisms that change their niches during the life cycle," American Naturalist, vol. 139, no. 5, pp. 990-1021, 1992.

[53] J. T. Haug, D. Audo, S. Charbonnier, and C. Haug, "Diversity of developmental patterns in achelate lobsters-today and in the Mesozoic," Development Genes and Evolution, vol. 223, no. 6, pp. 363-373, 2013.

[54] F. Palero, P. F. Clark, and G. Guerao, "Achelata," in Atlas of Crustacean Larvae, J. W. Martin, J. Olesen, and J. T. Høeg, Eds., pp. 272-278, Johns Hopkins University Press, Baltimore, Md, USA, 2014.

[55] E. G. Fagetti, "Larval development of the spider crab Pisoides edwardsi (Decapoda, Brachyura) under laboratory conditions," Marine Biology, vol. 4, no. 2, pp. 160-165, 1969.

[56] G. D. Bosquette, “The larval development of Pinnixa longipes (Lockington, 1877) (Brachyura: Pinnotheridae), reared in the laboratory," Biological Bulletin, vol. 159, no. 3, pp. 592-605, 1980.

[57] G. Guerao and P. Abelló, "Larval development of the spider crab Macropodia longipes (Brachyura: Majidae: Inachinae)," Journal of Crustacean Biology, vol. 17, no. 3, pp. 459-471, 1997.
[58] J. A. Cuesta, M. U. García-Guerrero, A. Rodríguez, and M. E. Hendrickx, "Larval morphology of the sesarmid crab, Aratus pisonii (H. Milne Edwards, 1837) (Decapoda, Brachyura, Grapsoidea) from laboratory-reared material," Crustaceana, vol. 79, no. 2, pp. 175-196, 2006.

[59] J. W. Martin, "Brachyura," in Atlas of Crustacean Larvae, J. W. Martin, J. Olesen, and J. T. Høeg, Eds., pp. 295-310, Johns Hopkins University Press, Baltimore, Md, USA, 2014.

[60] R. H. Gore, "Petrolisthes tridentatus: the development of larvae from a Pacific specimen in laboratory culture with a discussion of larval characters in the genus (Crustacea: Decapoda: Porcellanidae)," Biological Bulletin, vol. 141, no. 3, pp. 485-501, 1971.

[61] F. E. MacMillan, “The larval development of northern California Porcellanidae (Decapoda, Anomura). I. Pachycheles pubescens Holmes in comparison to Pachycheles rudis Stimpson," Biological Bulletin, vol. 142, no. 1, pp. 57-70, 1972.

[62] P. A. McLaughlin, R. H. Gore, and J. A. Crain, "Studies on the provenzanoi and other pagurid groups: II. A reexamination of the larval stages of Pagurus hirsutiusculus hirsutiusculus (Dana) (Decapoda: Anomura: Paguridae) reared in the laboratory," Journal of Crustacean Biology, vol. 8, no. 3, pp. 430-450, 1988.

[63] K. D. Bidle and P. A. McLaughlin, "Development in the hermit crab Pagurus caurinus Hart (Decapoda: Anomura: Paguridae) reared in the laboratory. Part I. Zoeal and megalopal stages," Journal of Crustacean Biology, vol. 12, no. 2, pp. 224-238, 1992.

[64] A. Harvey, C. B. Boyko, P. McLaughlin, and J. W. Martin, "Anomura," in Atlas of Crustacean Larvae, J. W. Martin, J. Olesen, and J. T. Høeg, Eds., pp. 283-294, Johns Hopkins University Press, Baltimore, Md, USA, 2014. 

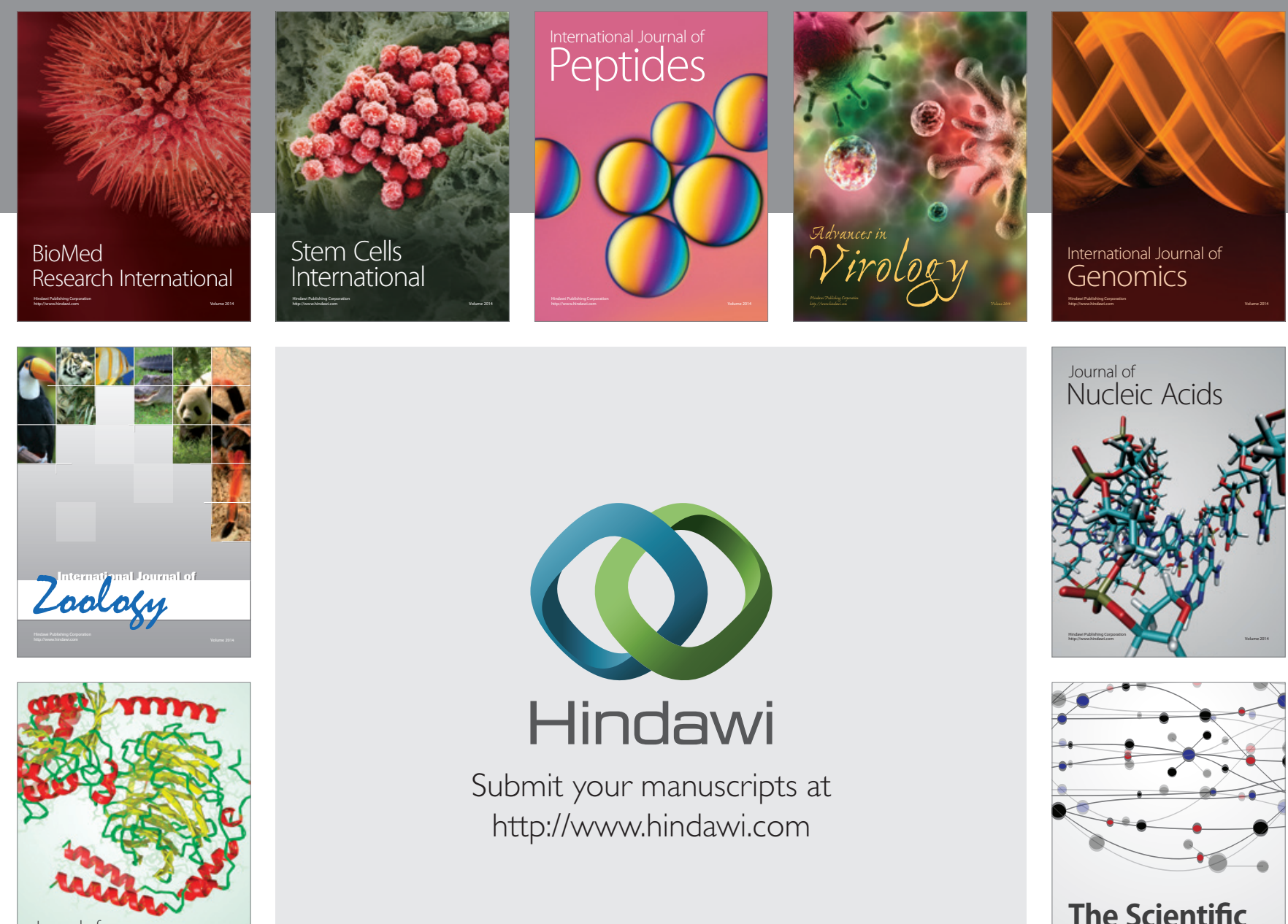

Submit your manuscripts at

http://www.hindawi.com

Journal of
Signal Transduction
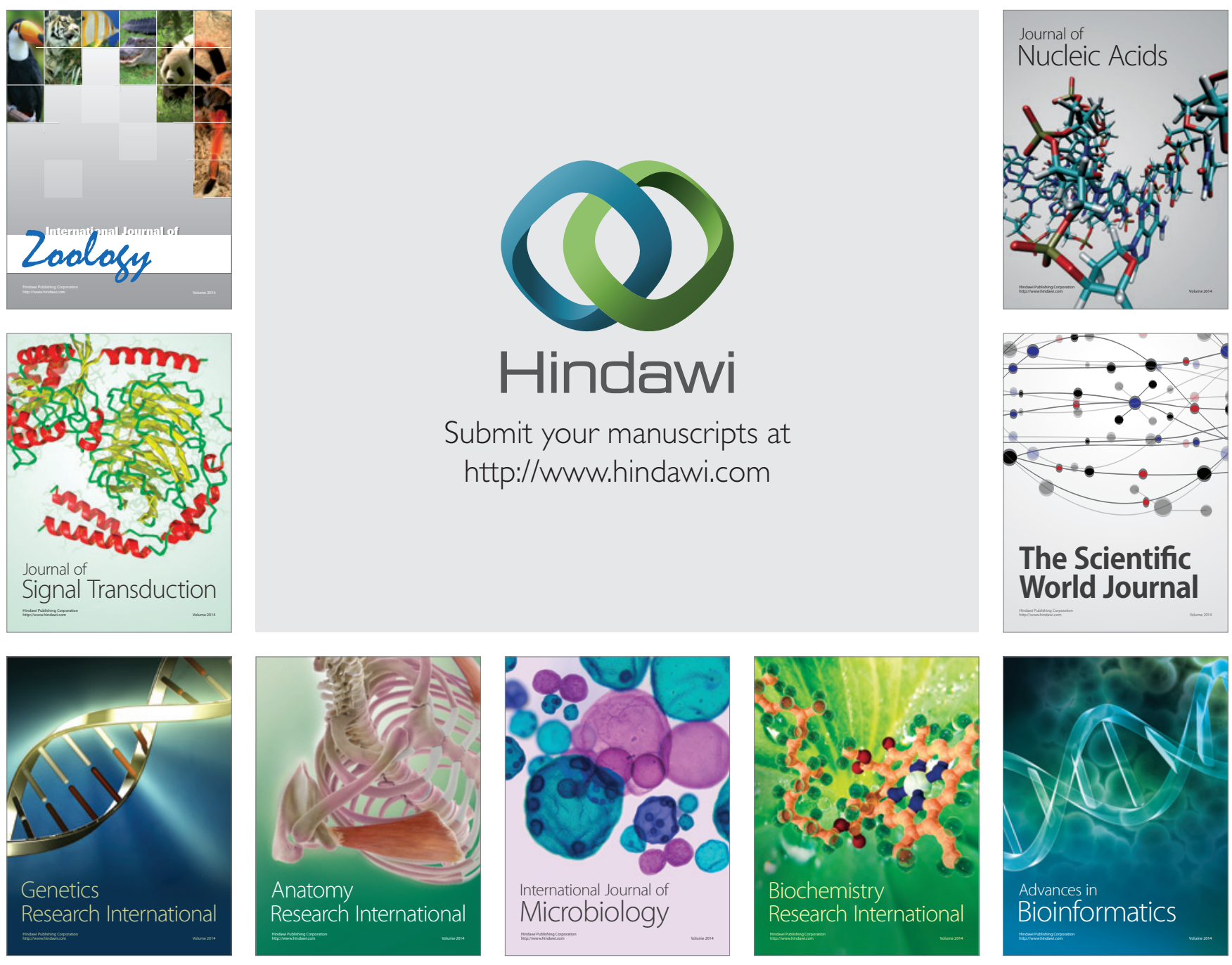

The Scientific World Journal
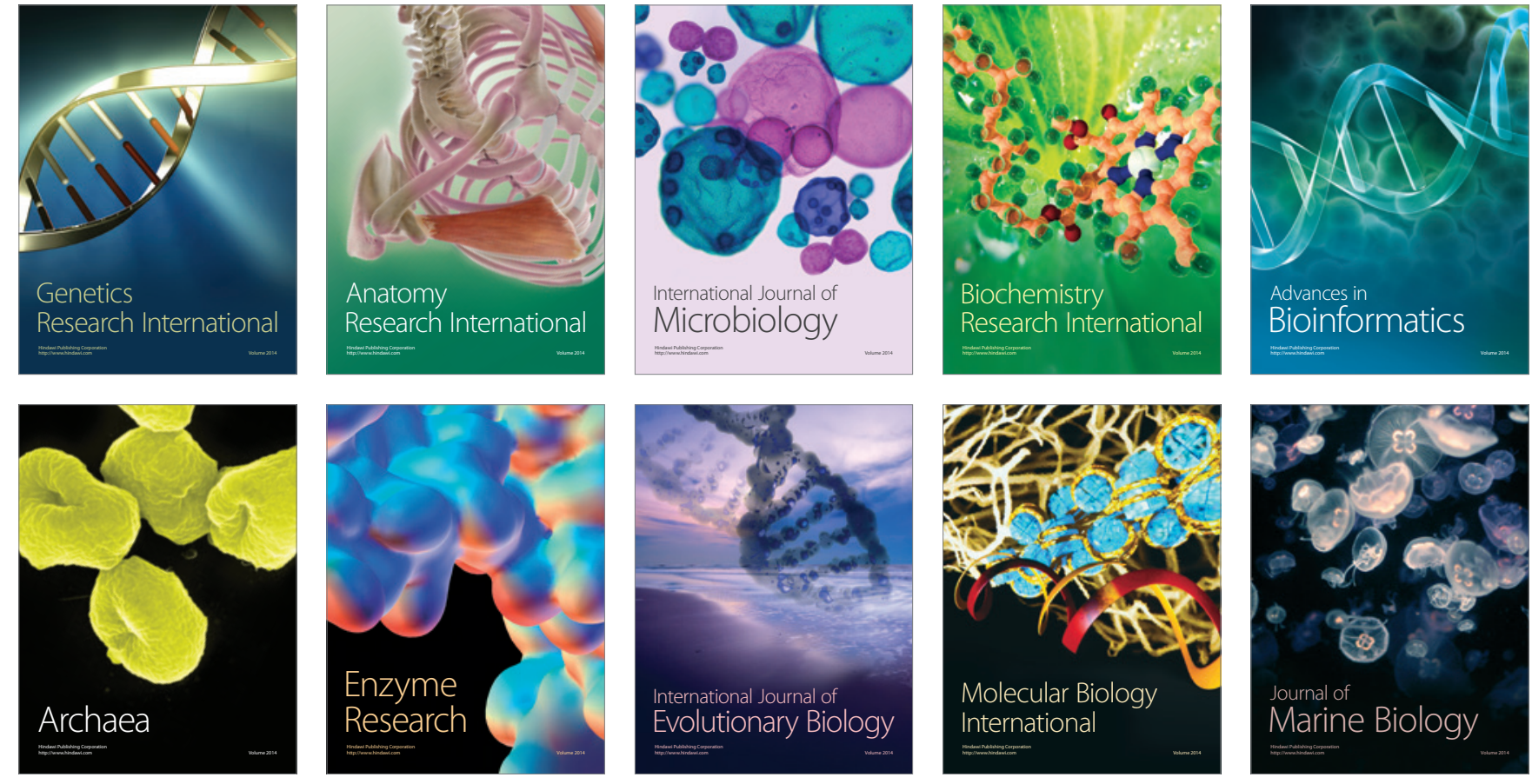